\title{
A systematic approach in the diagnosis of paediatric skull lesions: what radiologists need to know
}

\author{
Gagandeep Choudhary ${ }^{1 \mathrm{E}, \mathrm{F}}$, Unni Udayasankar ${ }^{2 \mathrm{E}, \mathrm{F}}$, Charbel Saade ${ }^{3 \mathrm{E}, \mathrm{F}}$, Blair Winegar ${ }^{2 \mathrm{E}, \mathrm{F}}$, Gilbert Maroun ${ }^{4 \mathrm{E}, \mathrm{F}}$, \\ Jad Chokr ${ }^{5 E, F}$
}

'Department of Radiology, University of Alabama at Birmingham, Birmingham, AL, USA

2Department of Medical Imaging, Division of Paediatric Neuroradiology, Banner University Medical Centre, Tucson, Arizona, USA

${ }^{3}$ Faculty of Health Sciences, American University of Beirut, Lebanon

${ }^{4}$ Department of Medical Imaging, American University of Beirut Medical Center, Lebanon

${ }^{5}$ Department of Medical Imaging, Clemenceau Medical Center, affiliated with Johns Hopkins International, Beirut, Lebanon

\section{Abstract}

Paediatric skull lesions are commonly identified on imaging. They can be challenging to image, given their location and size, and often require several imaging modalities to narrow down the differential diagnosis. Accurate diagnosis of these lesions is paramount because the clinical therapy can vary tremendously. In this review, we provide a simple and systematic approach to clinical-radiological features of primary skull lesions. We highlight the imaging characteristics and differentiate pathologies based on imaging appearances. We also accentuate the role of cross-sectional imaging in lesion identification and management implications.

Key words: skull lesions, paediatric skull, cross-sectional, computed tomography, magnetic resonance imaging.

\section{Introduction}

Skull lesions in the paediatric population are common entities and often constitute a diagnostic dilemma for radiologists. A wide spectrum of lesions exists, which includes congenital, traumatic, infectious, neoplastic, vascular, and post-surgical abnormalities during imaging pathways. The wide array of differential diagnoses challenges the radiologists to identify the lesion as either benign or malignant in nature. Providing a systematic pathway to diagnosis increases the reader's confidence in accurately diagnosing these lesions, whether it is an incidental or palpable abnormality (Figure 1). Depending on the age of the patient, certain pathologies predominate; in neonates and infants, congenital and benign lesions are more prevalent, whereas in older children, neoplastic and inflammatory origins are to be considered (whether symptomatic or asymptomatic).
Imaging modalities such as thin-section computed tomography (CT), multi-parametric magnetic resonance imaging (MRI), and sonography (US) are essential to define the origin, nature, and extent of these lesions. The aim of this review is to provide radiologists with a simple and systematic approach to the characterisation, detection, and differential diagnosis of paediatric skull lesions.

\section{Congenital}

\section{Congenital depression of the skull}

Congenital depression of the skull is rare, with an estimated incidence of $<0.0001 \%$ [1]. Most of these cases are probably related to trauma during difficult labour, by obstetric manoeuvres or pressure from forceps. In the absence of trauma or risk factors, reports of depressed skull

Correspondence address:

Dr. Jad Chokr, Department of Medical Imaging, Clemenceau Medical Center, affiliated with Johns Hopkins International, Clemenceau Street, Beirut,

Lebanon 11-2555, e-mail:jad_1986@hotmail.com

Authors' contribution:

A Study design · B Data collection · C Statistical analysis · D Data interpretation · E Manuscript preparation · F Literature search · G Funds collection 


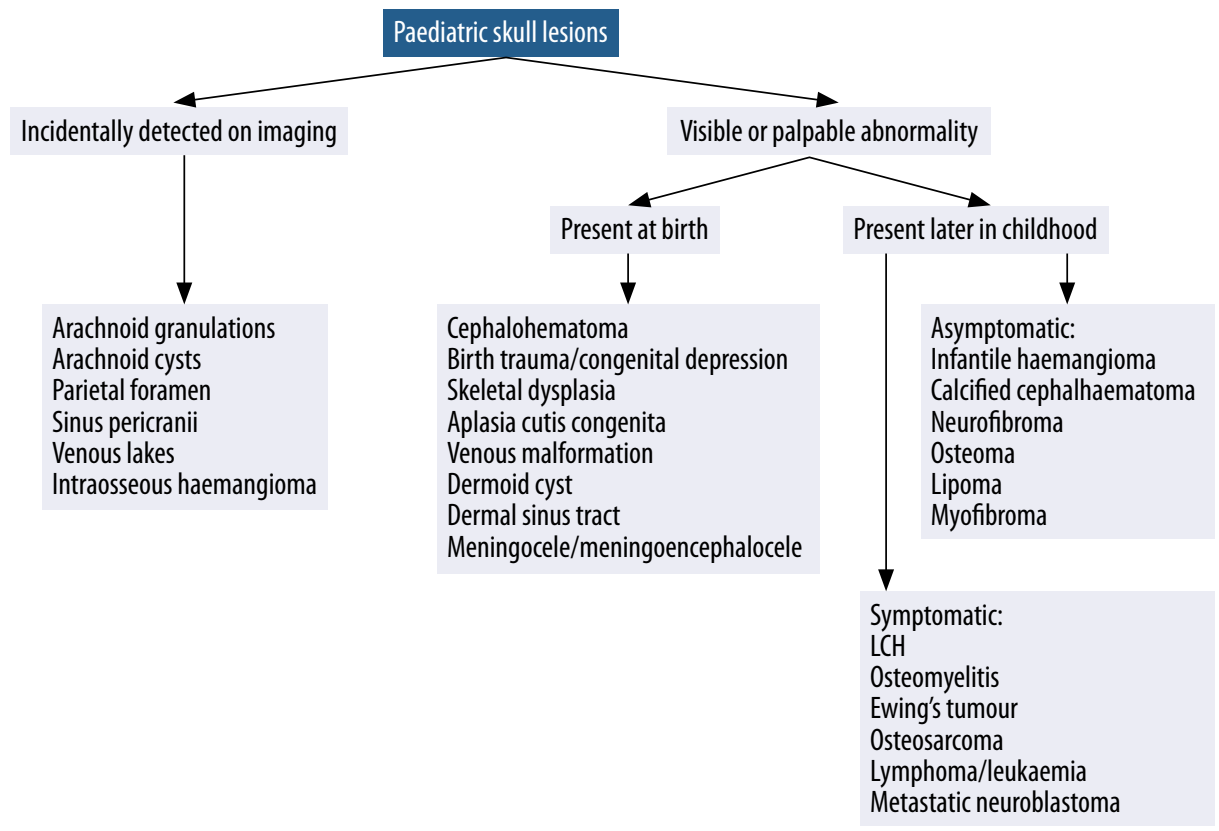

Figure 1. Imaging pathways of skull lesions in the paediatric population

fractures are rare [1-7]. In a small number of reported cases, intrauterine events have been thought to be the cause. Other postulated risk factors include pressure on the soft foetal skull from maternal structures such as ischial spines, fifth lumbar vertebrae, pubic symphysis, asymmetric or contracted pelvis, and uterine myomas [8-10]. Skull depressions may occur with or without fractures and can be classified as linear, depressed, or 'ping-pong' fractures and occipital osteodiastasis [11]. They most frequently occur in the temporal and parietal bones [12]. In the majority of cases, neonates are neurologically intact; deficits are a rare association, often secondary to intra- or extra-axial haematomas.

Computed tomography of the head is usually the modality of choice. It reveals fractures, secondary haematomas, and brain compression, all of which would require aggressive treatment [10] (Figure 2). Magnetic resonance imaging is indicated if there is suspicion of structural brain anomalies. The majority of skull depressions resolve spontaneously within 4-6 months, and in the absence of neurological symptoms, a conservative approach with a six-month observation period is advised $[13,14]$.

\section{Frontonasal dysplasia}

Frontonasal dysplasia (FND), also known as Tessier cleft, median cleft face syndrome, frontonasal dysostosis, or frontonasal malformation, is a congenital malformation of the midface [15]. While its cause is still unknown, environmental and genetic factors may play a role $[16,17]$.

Diagnostic criteria for FND are a wide nasal root, hypertelorism, vertical midline cleft of the nose and/or upper lip, cleft of the wings of the nose, malformed nasal tip, or V-shaped hair pattern on the forehead [15]. Patients can present with at least two of the above-mentioned signs to be labelled with FND. There are two different categories of mid-facial malformations. The first is with hypertelorism, which includes FND. The second is with hypo-
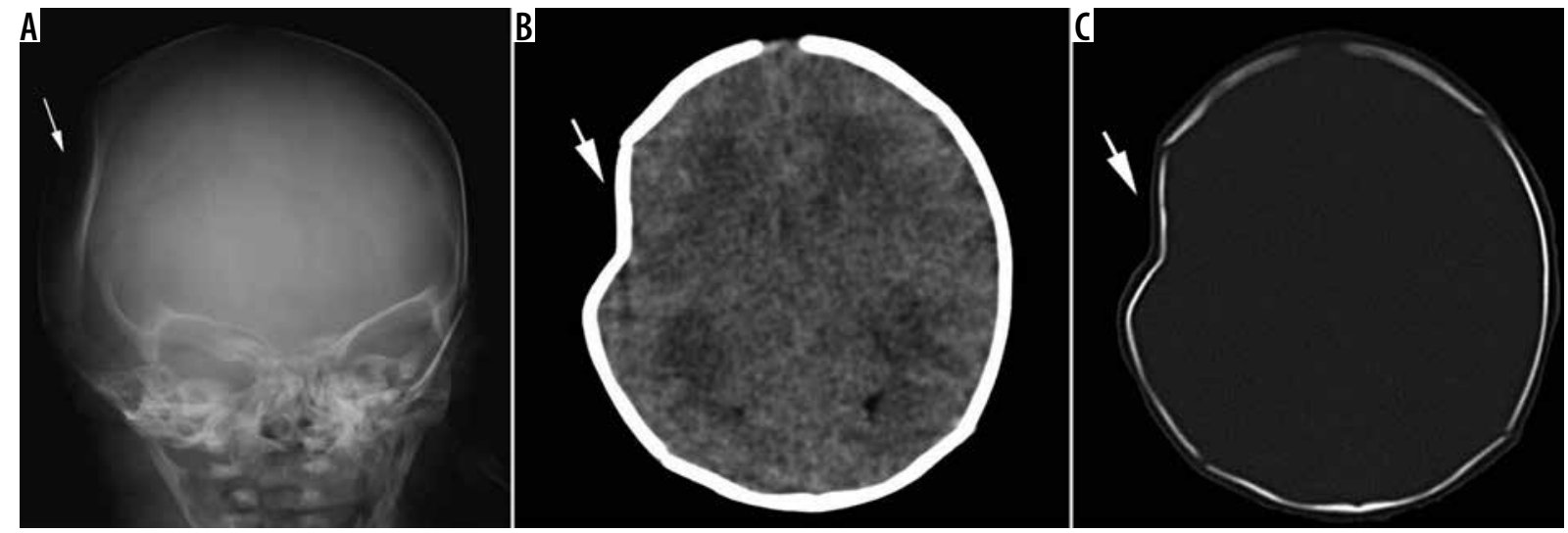

Figure 2. A) Skull film shows focal depression of right anterior parietal skull (arrow). B, C) Axial head computed tomography with soft tissue and bone windows show abnormal contour and depression of the right calvarium. No acute fractures were identified 

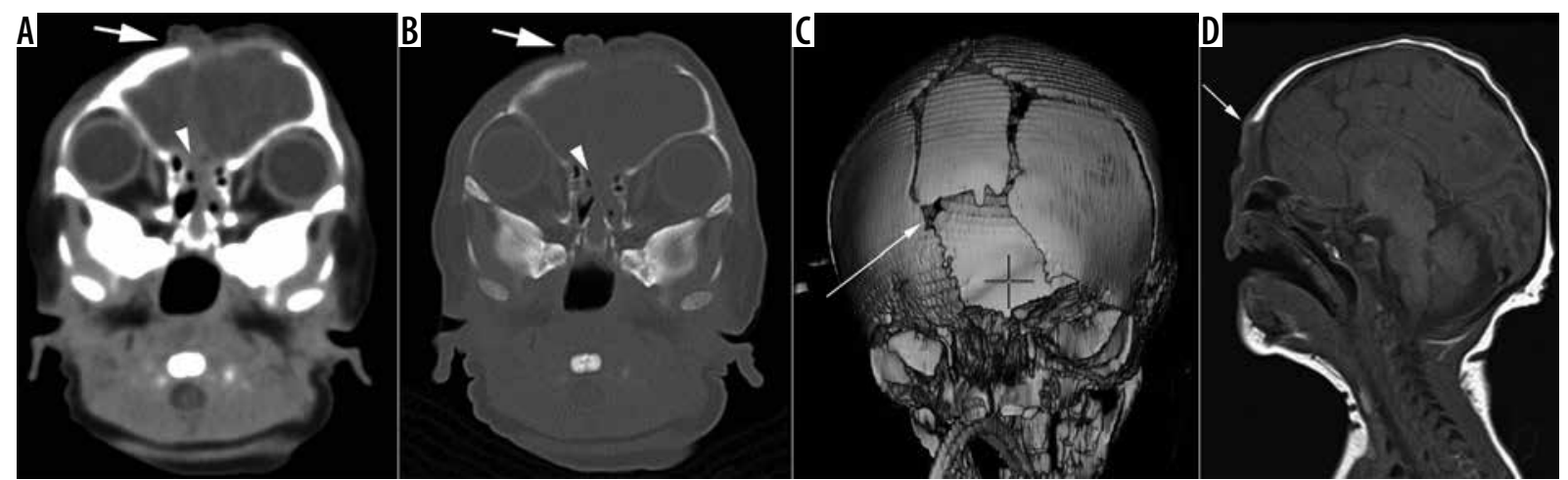

Figure 3. Four-month-old girl with frontonasal dysplasia. A, B) Axial head computed tomography images in brain and bone windows show midline nasal and frontal calvarial defects with associated telecanthus. C) 3D reformat and (D) sagittal T1-W images show a large defect in the frontal calvarium

telorism and includes holoprosencephaly $[18,19]$. Plain films and computed tomography of the skull are crucial for planning surgery (Figure 3) [20]. Prenatal ultrasound can depict various features of FND $[21,22]$. The first goal of postnatal treatment is to establish a proper airway because newborns can only breath through the nose [23].

\section{Aplasia cutis congenita}

Aplasia cutis congenita (ACC) can be clinically diagnosed; defined as the congenital absence of the skin, it presents with a focal ulcer over the vertex of the skull $[24,25]$. The cause of ACC remains obscure, with various aetiologies suggested $[26,27]$. The defect involves the calvaria and the dura mater, with $20-30 \%$ of cases presenting with associated anomalies [25,28-31]. While the majority of children have a single defect, it is doubled in $20 \%$ and may involve the trunk or limbs [32-38]. Larger defects revealing the dura and sagittal sinus require treatment at birth to avoid complications such as meningeal infection and haemorrhage. If ACC occurs as a small focal ulcer, it heals spontaneously [34,37]. However, when the defect is large, surgery is performed to prevent complications [31].

Conventional radiographs of the skull demonstrate bony defects at the level of the absent skin. MRI or CT clearly delineates intracranial malformations and demonstrates the proximity of the scalp/skull defects and underlying sagittal sinus (Figure 4A-C). Ultrasound is recom- mended to look for associated visceral malformations [39-42]. The larger defects are invariably associated with a skull defect, with the dura and brain covered only by an ulcer or a thin membrane (Figure 4D) [29,31,32,37].

\section{Arachnoid granulations}

Arachnoid granulations, also known as Pacchionian granulations, are focal invaginations of the leptomeninges into the venous sinuses $[43,44]$. Their most common location is within the superior sagittal sinus, followed in decreasing frequency by the transverse and cavernous sinus [43-45]. Arachnoid granulations increase in number and size with age and are frequently found at venous entry sites into the sinus [44-48].

CT demonstrates granulations as cerebrospinal fluid (CSF) density invaginating into the calvarium or a dural venous sinus resulting in a filling defect (Figure 5). They may be confused with venous sinus thrombosis but are usually differentiated by their classic location and round, well-defined shape. Similarly, on MRI, signal characteristics are those of CSF (low T1, high T2, and suppressed on FLAIR).

\section{Arachnoid cysts}

Arachnoid cysts are congenital intra-arachnoidal lesions filled with CSF, which do not communicate with the ven-
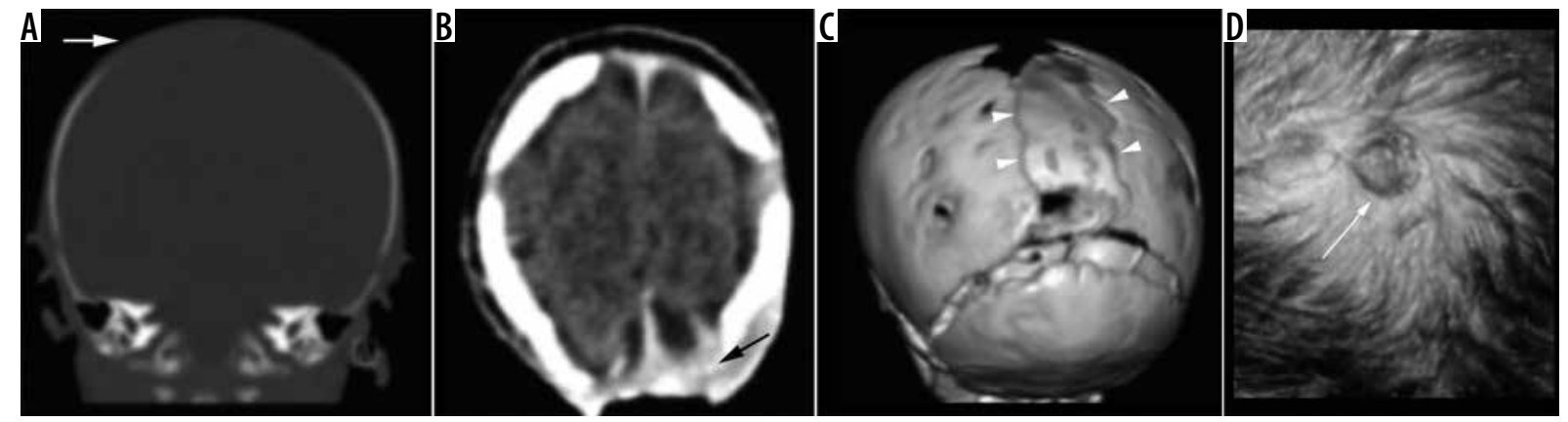

Figure 4. A) Coronal, B) axial head computed tomography angiography show a large left paramidline skull defect (white arrow) and an associated scalp defect, where the superior sagittal sinus abuts and extends to the cutaneous surface (black arrow). C) 3D reformat shows the skull defect and scattered small parietal foramina. D) Clinical image of scalp ulcer/wound 

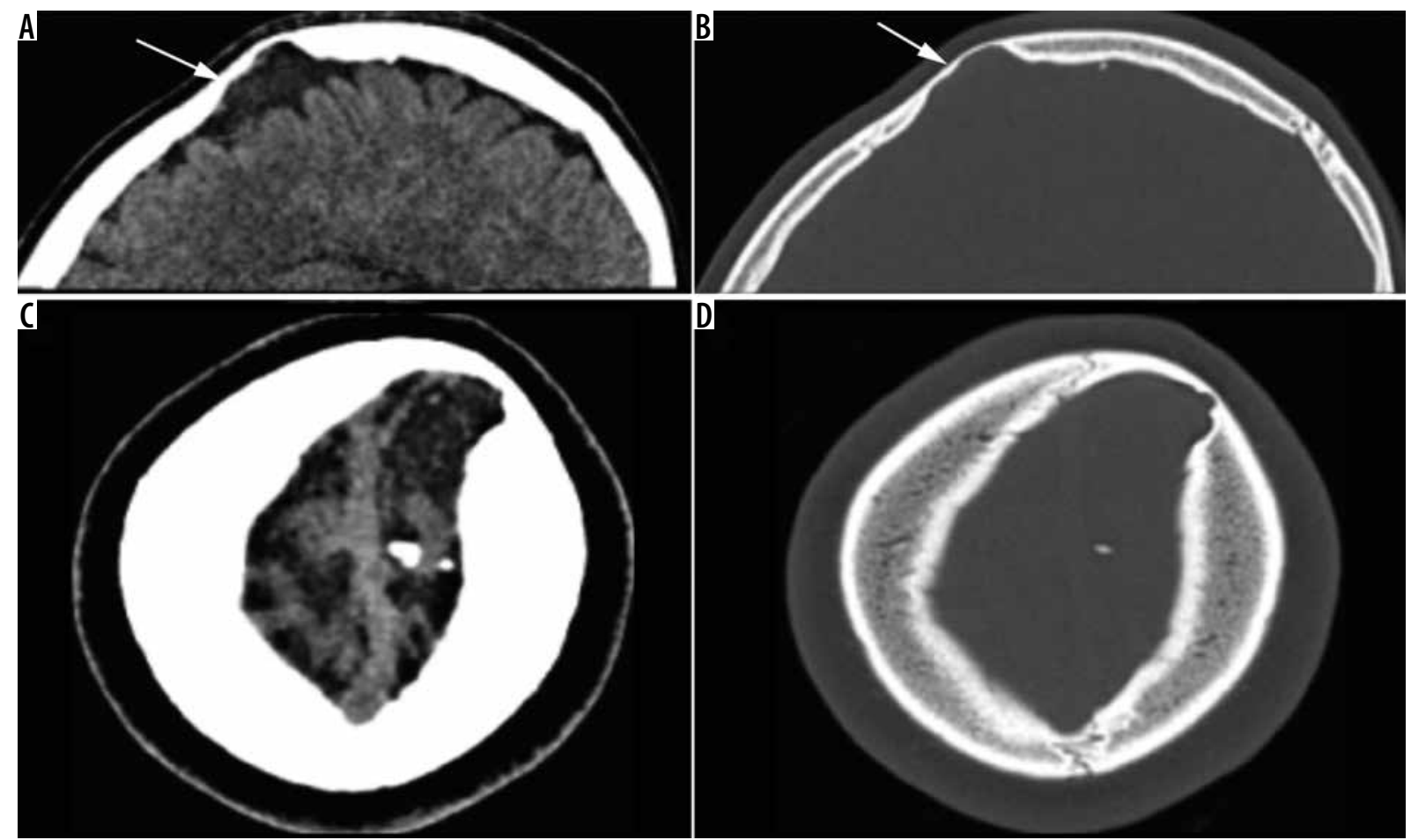

Figure 5. A, B) Sagittal and (C, D) axial head computed tomography images on brain and bone window show a prominent arachnoid granulation with scalloping of the calvarial inner table
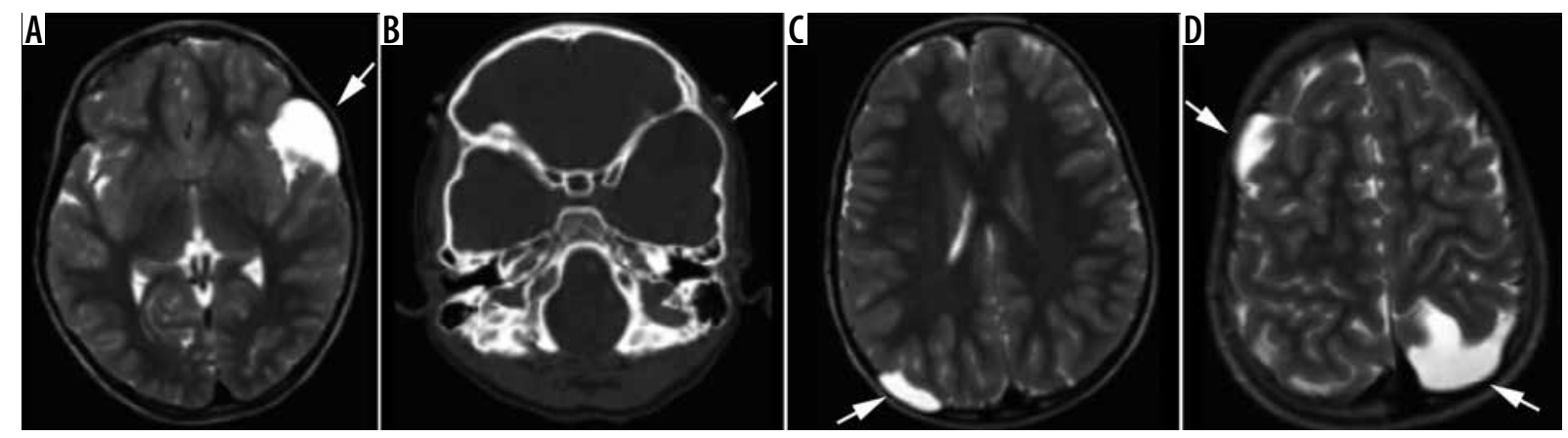

Figure 6. Five-year-old girl with multiple arachnoid cysts and clinically visible swelling. A, B) Axial head computed tomography images show extra-axial cerebrospinal fluid (CSF) signal lesion in the left temporal region with scalloping of the inner table of the skull and bulging overlying skull. C, D) Axial T2-W images show extra-axial CSF signal cystic lesions exerting mild mass effect on the adjacent brain parenchyma and skull

tricles. They are most frequently unilocular, well-marginated lesions moulded by nearby structures. Arachnoid cysts are common, representing $1 \%$ of all intracranial masses [49]. Most cysts are supratentorial in location, with $50-60 \%$ in the middle cranial fossa, anterior to the temporal lobes. Other common locations include the suprasellar cistern and posterior fossa (10\%), particularly in the cerebellopontine angle cistern. Arachnoid cysts are usually stable in size, however cases of enlargement as well as resolution, have been published [50-54]. They can present from small and incidental to very large with mass-effect on the underlying brain $[49,51,52]$.

Imaging demonstrates a well-delineated extra-axial cyst with CSF density/signal that can result in a mass effect on the adjacent brain, with scalloping of the inner table (Figure 6). Classically, no identifiable internal architecture or enhancement is seen. Rarely, high-protein con- tent or haemorrhage within the cyst may render diagnosis rather difficult $[49,51,52]$.

\section{Dermoid/epidermoid cyst}

Dermoid and epidermoid cysts result from persistent ectodermal elements at sites of suture or neural tube closure, as well as diverticulation of the cerebral hemispheres $[55,56]$. Dermoids are composed of ectoderm and skin elements, whereas epidermoids contain exclusively ectodermal elements. Both are most commonly seen in the midline, frontal, and temporal regions.

CT appearances change depending on constitution, with fatty density with dermoids and fluid density with epidermoid cysts. Similarly, MRI signal (Figures 7 and 8) depends on the content, ranging from a fluid signal in an epidermoid cyst to a fat-containing signal in a dermoid. 


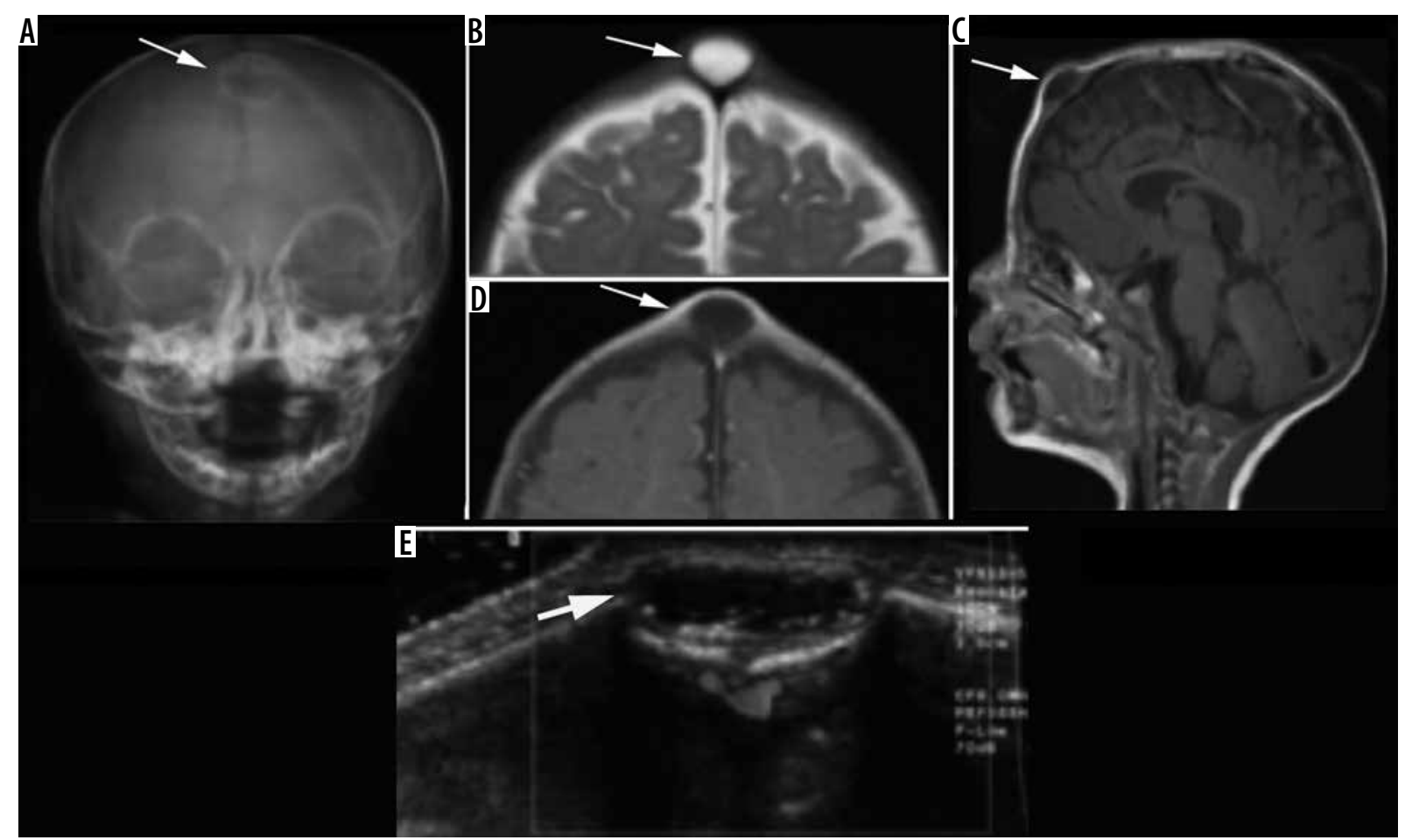

Figure 7. One-year-old male patient with epidermoid cyst. A) Frontal X-ray of the skull shows a well-demarcated lytic lesion with sclerotic borders involving the frontal bone at the midline. B-D) Axial T2, axial T1 post contrast, and sagittal T1 images show an oval shaped non-enhancing cystic lesion involving the frontal bone with expansion of the diploic space. E) Ultrasonography shows an oval shaped homogeneous lesion with hypoechogenic internal structure, hyperechogenic surrounding wall, and no obvious flow on colour Doppler
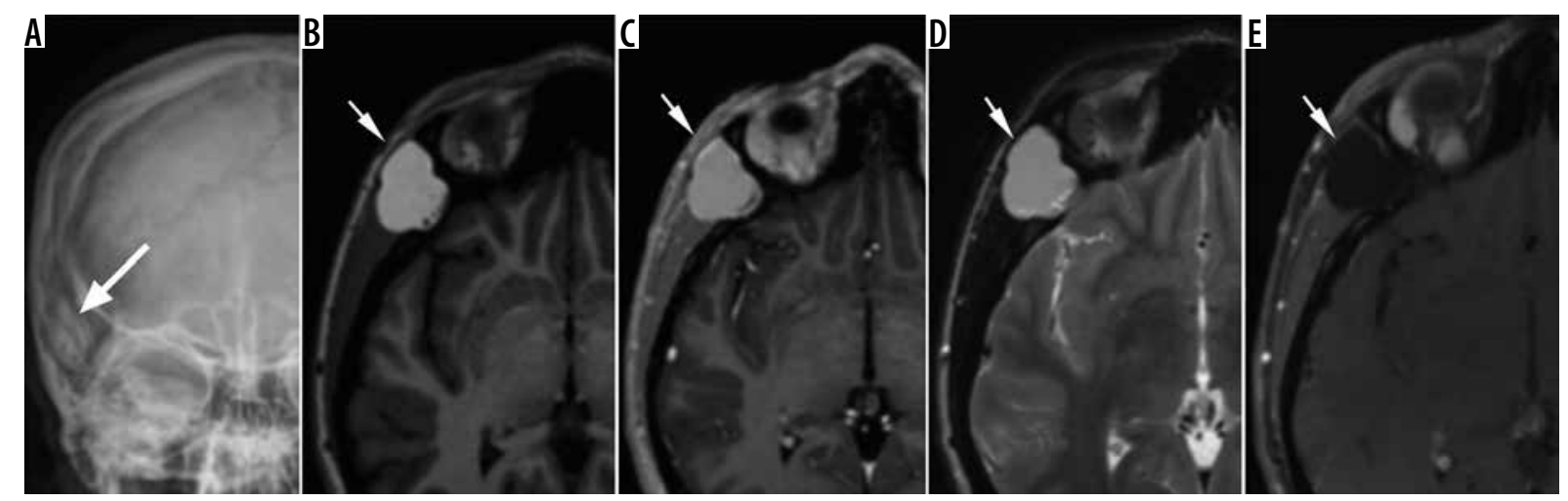

Figure 8. Right periorbital dermoid cyst. A) Frontal X-ray of the skull shows an ill-defined lytic lesion involving the right temporal bone. B-E) Axial T1, $\mathrm{T} 1$ post contrast, $\mathrm{T} 2$ and $\mathrm{T} 1$ fat-sat post-contrast images, respectively, shows a fat-containing lesion expanding the right temporal bone with thin peripheral enhancement

Epidermoid cysts characteristically have high signal on the diffusion-weighted sequence $[57,58]$. On ultrasound, dermoid cysts demonstrate hypoechogenic internal structure and hyperechogenic surrounding wall with no active blood flow.

\section{Parietal/bi-parietal foramen}

Parietal foramina represent a disorder of calvarial ossification. At birth, either a large single midline or bilateral calvarial defects are present, with the brain covered by a dura, pericranium, and overlying scalp. Defects usually close in mid-childhood, leaving symmetrical foramina [59].
A familial incidence with autosomal dominant inheritance has been identified with specific gene mutations discovered [60-62].

The pathology is believed to be benign; however, cross-sectional imaging with CT and MRI has uncovered associated intracranial anomalies, particularly abnormal venous development. CT images demonstrate either a single or paired rounded defect(s) at the level of the parietal bone adjacent to the intersection of the sagittal and lambdoid sutures (Figure 9). Defects may be large and unified across the midline. MRI is the modality of choice for detecting associated venous, cortical, or meningeal abnormalities. 

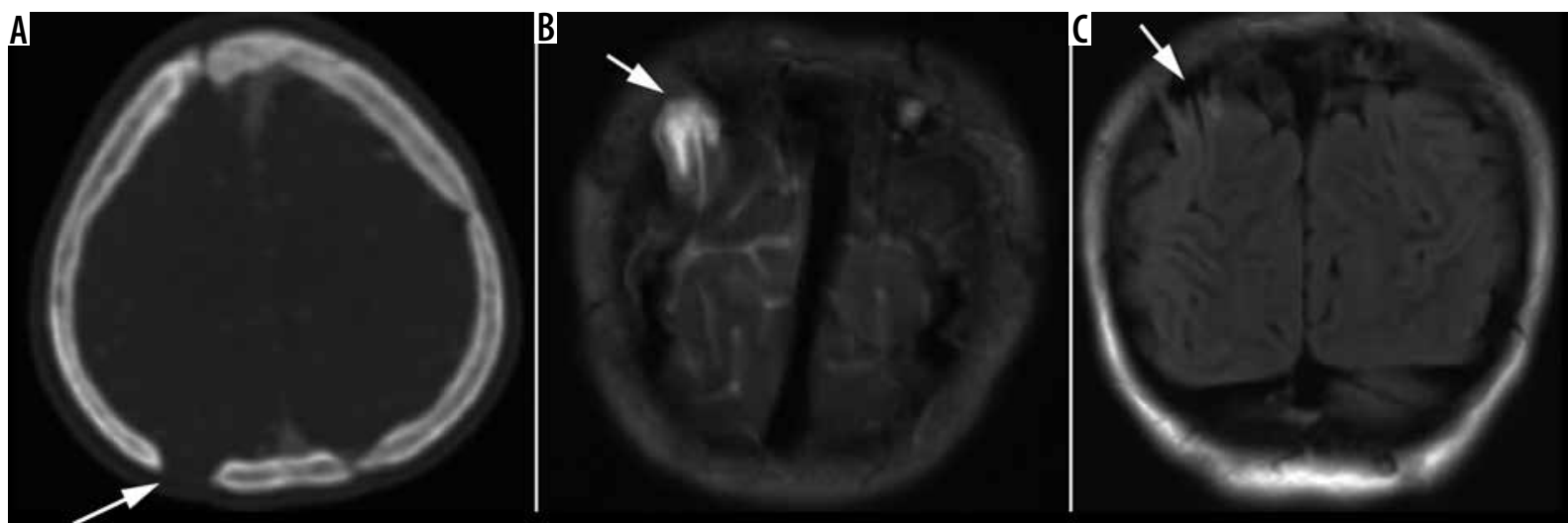

Figure 9. Ten-year-old boy with right parietal foramen. A) Axial computed tomography, B) T2-W, and (C) coronal Gd-enhanced T1-W show a prominent right parietal foramen (arrows)
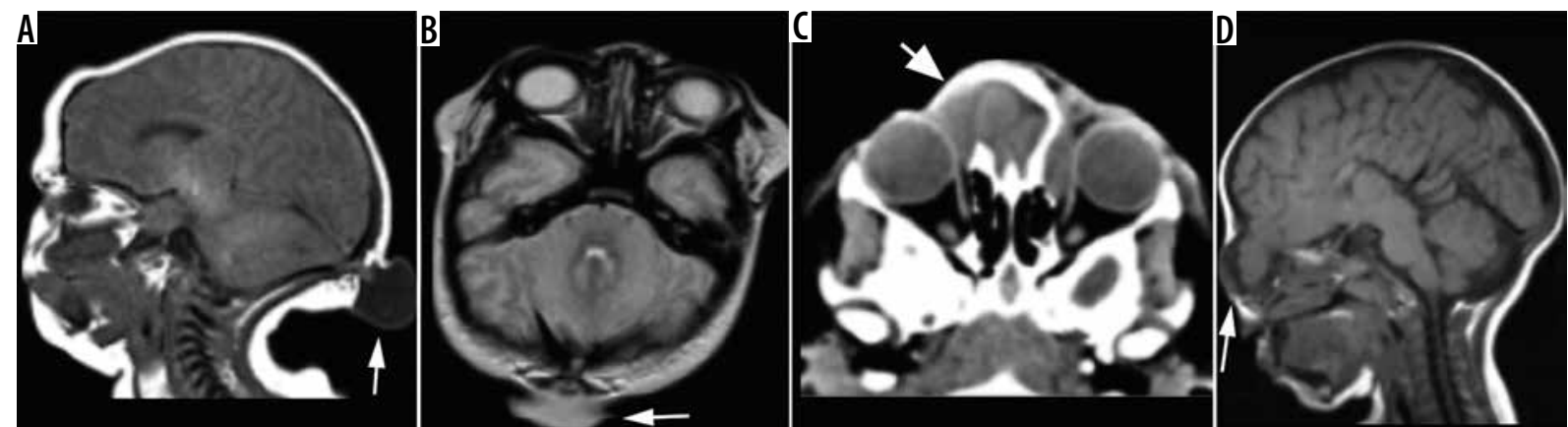

Figure 10. Occipital encephalocele. A) Sagittal T1-W and (B) axial T2-W images show a small midline defect with a herniated sac containing cerebrospinal fluid and a small portion of the cerebellar parenchyma (arrow). Naso-ethmoidal encephalocele. C) Axial non-enhanced computed tomography and (D) sagittal T1-W images show midline brain tissue mass protruding through a defect in the cribriform plate as well as agenesis of the corpus callosum

\section{Encephalocele}

Encephalocele is the herniation of intracranial tissue through a defect in the skull [63-65]. When they contain only meninges, they are called meningoceles, or meningoencephaloceles if brain tissue is also included. They are most commonly occipital in location (75\%); $15 \%$ are frontoethmoidal and the remaining cases are basal [64]. Occipital encephaloceles may be seen with Chiari or DandyWalker malformations as well as callosal or migrational anomalies [66-68]. Frontoethmoidal encephaloceles known as sincipital encephaloceles are divided into nasofrontal, nasoethmoidal, and naso-orbital types [69-71]. The intracranial extent of the majority of frontoethmoidal encephaloceles lies at the foramen caecum $[64,65]$. Basal encephaloceles are not generally visible externally, although they may manifest as a mass in the oropharynx or nasopharynx.

Atretic encephaloceles are also included in the differential of skin-covered midline scalp masses. The most common location is parietal, and they usually contain meninges and neural rests [72]. A vertically positioned straight sinus is commonly associated with this entity $[72,73]$. Atretic encephaloceles contain a fibrous stalk at their base that connects to the dura mater.

MRI is the modality of choice for determining the contents of an encephalocele preoperatively. CT is helpful to define the bone anatomy; however, the intracranial extent is best seen with MR (Figures 10,11). Occipital encephaloceles commonly involve the cerebellar or cerebral hemispheres and may involve the dural venous sinuses.

\section{Craniosynostosis: Crouzon syndrome}

Craniosynostosis was first described by Virchow in 1851 $[74,75]$ and is defined as a premature fusion of the cranial sutures that leads to characteristic abnormal morphologies of the cranium. Although craniosynostosis is seen in different syndromes, single sutural synostosis is most commonly an isolated finding [76,77].

Crouzon syndrome (CS) is an autosomal dominant condition, resulting from mutations in the FGFR-2 gene on chromosome 10q25-q26 [78,79]. It is characterised by the presence of craniosynostosis, midface hypoplasia with "beaked" nasal tip, midface retrusion, mandibular prognathism, and disproportionately striking exorbitism. Most commonly, patients with CS show bicoronal synostosis. The key finding in patients with CS is the notable absence of hand anomalies that affect other groups of patients with similar skull deformities. CT demonstrates diffuse morphological abnormality of the inner table of the skull, with areas of discontinuation in the calvarium, while 3D CT image reformations provide superior evaluation of sutures and preoperative planning (Figure 12). 

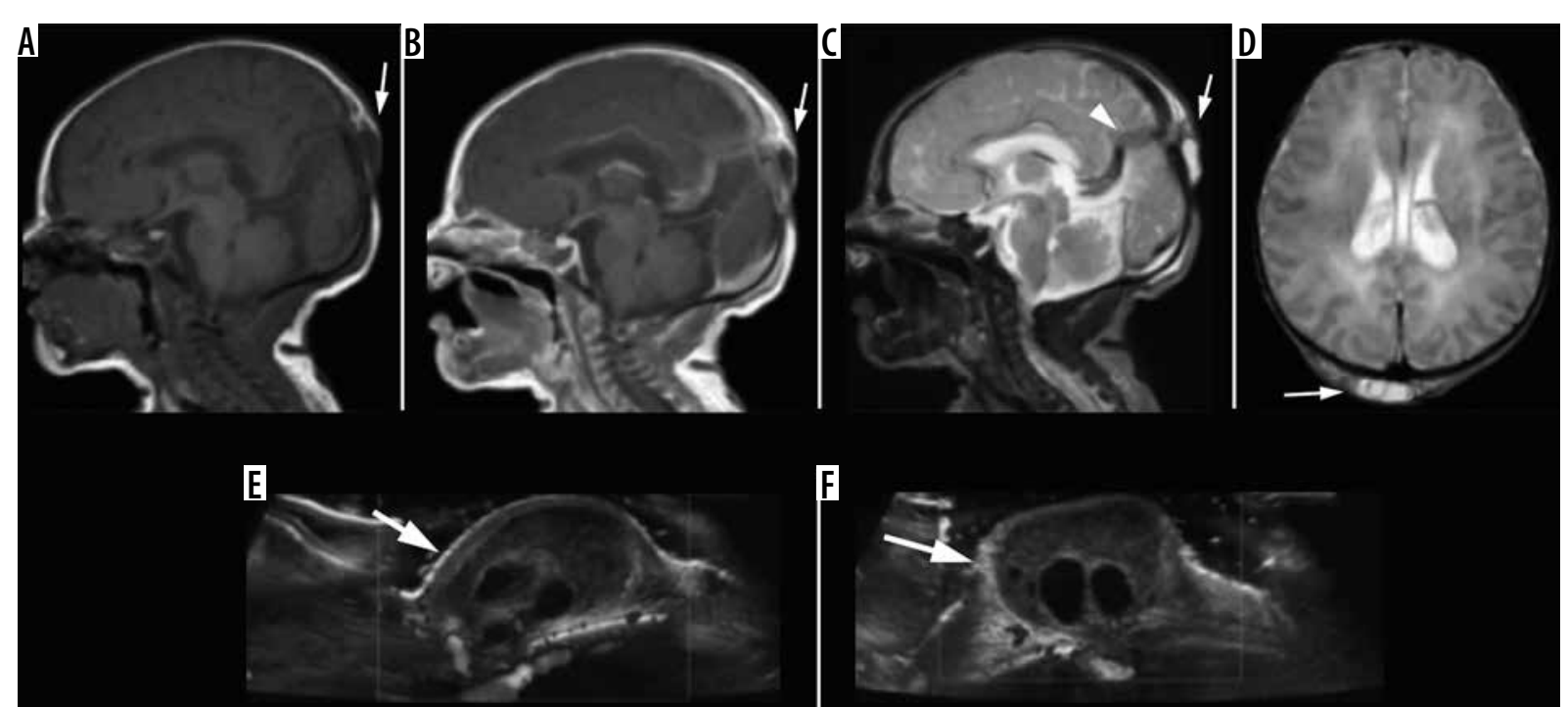

Figure 11. Atretic parietal encephalocele. A-C) Sagittal T1-W, post Gd T1W, T2W, and (D) axial T2W images demonstrate a slightly off-midline hyperintense T2 herniation sac through a parietal defect (arrows) and a persistent embryonic falcine sinus (arrow head) directed at the atretic cephalocele. Also note the absence of a straight sinus. E, F) Colour Doppler US images demonstrate the herniated sac containing fibro-fatty tissue
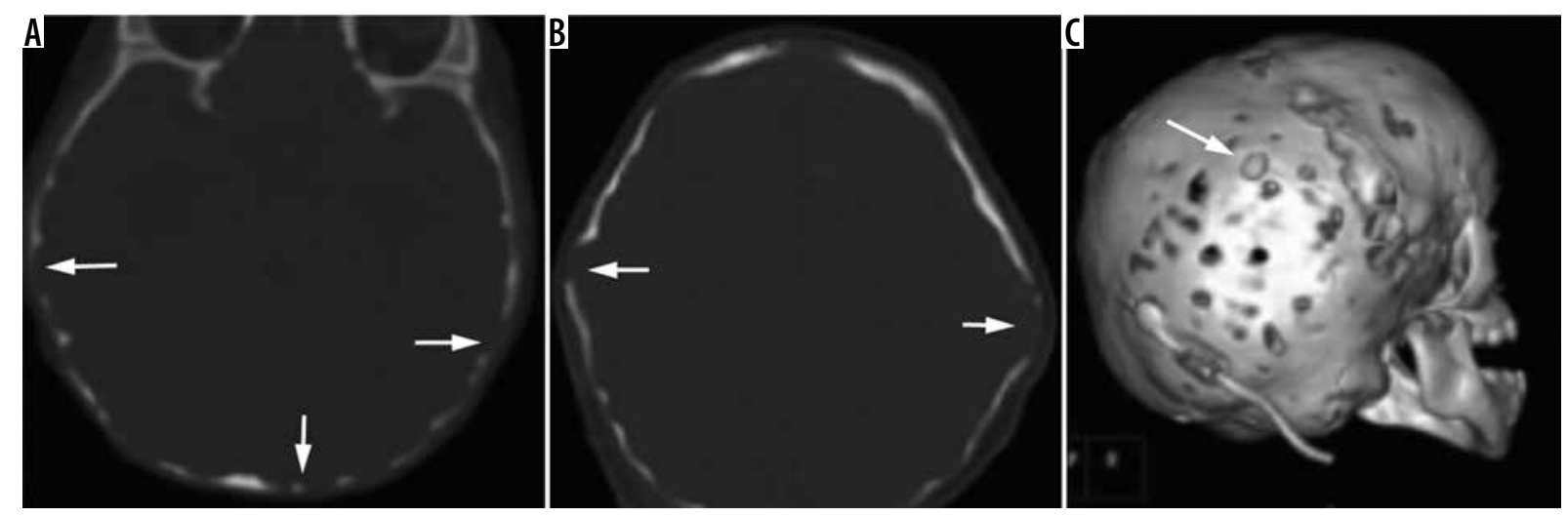

Figure 12. Five-month-old boy with Crouzon's syndrome and skull abnormality. A, B) Axial head computed tomography images on bone window show diffuse morphological abnormality of the inner table of the skull with areas of discontinuation in the calvarium. C) 3D reformat shows the gross bony abnormality and foramina. VP shunt in place for hydrocephalus decompression
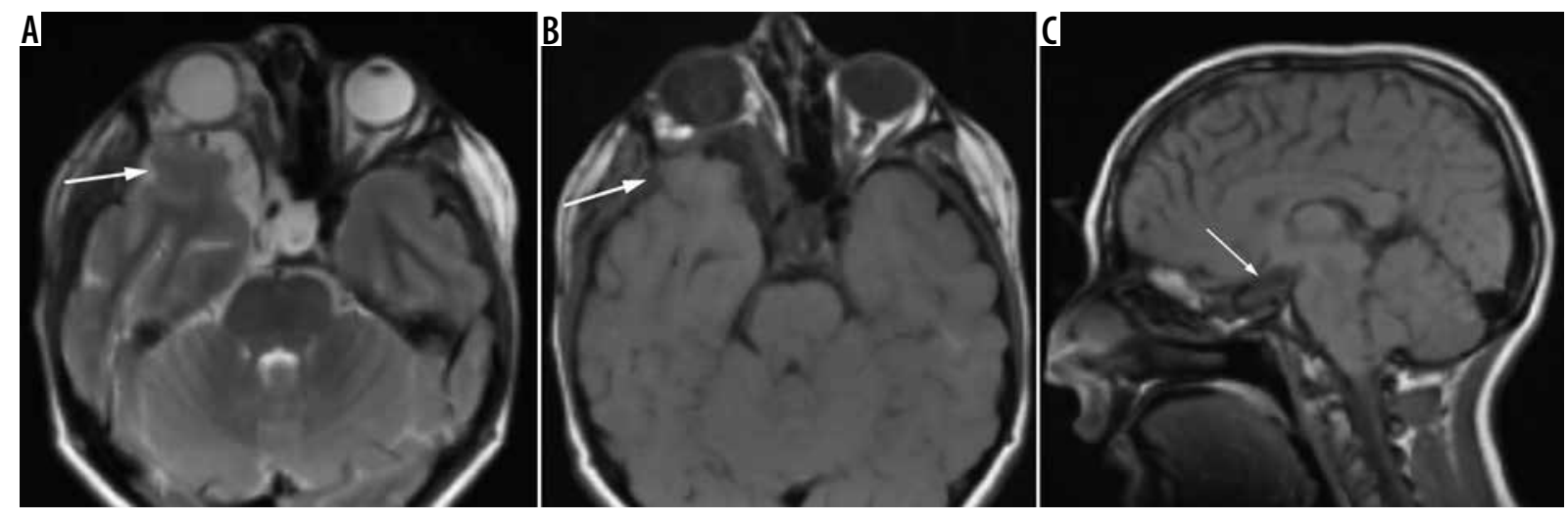

Figure 13. Twelve-year-old girl with neurofibromatosis type I and sphenoid wing dysplasia. A) Axial T2-W and (B) T1-W images show absence of the right sphenoid wing, expanded middle cranial fossa, and displaced contents with resultant right proptosis. C) Sagittal T1-WI shows absence of sella and sphenoid wing

\section{Sphenoid wing dysplasia}

Sphenoid dysplasia is a major but not pathognomonic feature of neurofibromatosis type 1 [80]. Imaging findings include middle cranial fossa enlargement, anterior displacement of the greater sphenoid wing (often in association with a temporal arachnoid cyst), widening of the superior orbital fissure, and elevation of the lesser sphenoid wing. There is also secondary ipsilateral orbital enlargement (Figure 13) [81]. 

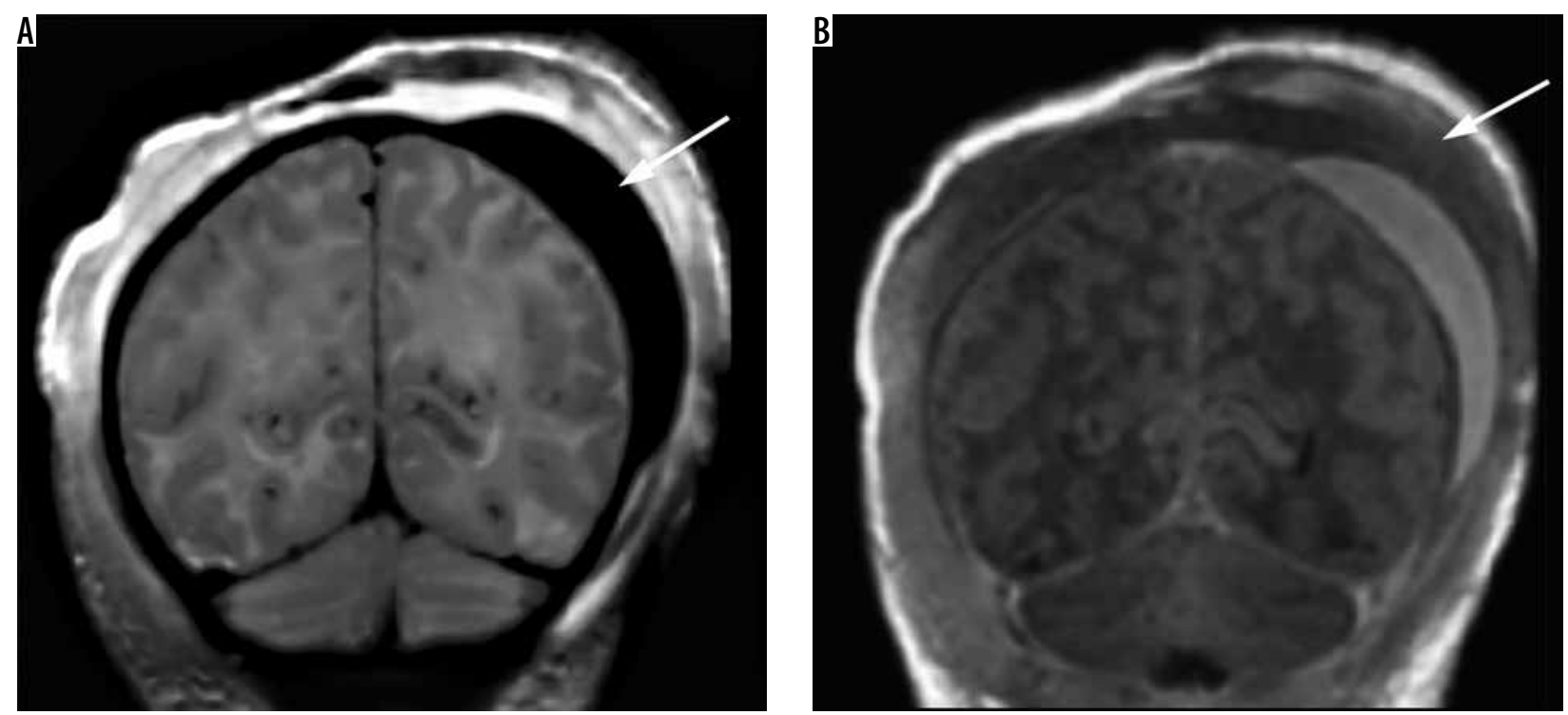

Figure 14. Newborn with both cephalohematoma and subgaleal fluid collection. A, B) Coronal T1- and flair-weighted images shows the presence of a cephalohematoma and subgaleal fluid collection respectively (arrows)
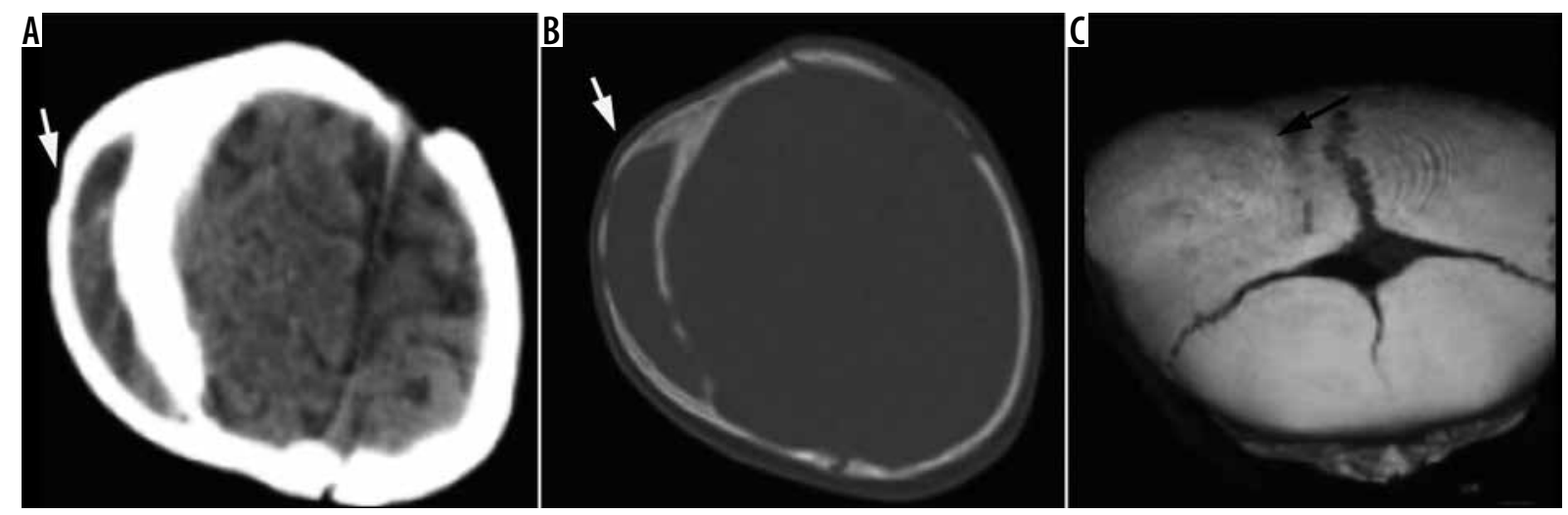

Figure 15. Five-month-old boy with enlarging right skull "mass". A, B) Axial head computed tomography in soft tissue and bone windows, respectively, shows a peripherally ossified subperiosteal haematoma. C) 3D surface rendered image demonstrates a large ossified lump in the area of concern

\section{Traumatic}

\section{Cephalohematoma}

Cephalohematoma is defined as a subperiosteal haemorrhage confined by cranial sutures, whereas caput succedaneum crosses sutures and is mostly located at the vertex. A subgaleal haematoma is below the aponeurosis covering the scalp and is not confined by suture lines (Figure 14). Cephalohematomas occur in 1-2\% of vaginal deliveries and $3-4 \%$ of assisted deliveries (vacuum or forceps) [82]. Chronic cephalohematomas calcify and have a typical clinical and radiologic appearance (Figure 15) [83]. They are usually of no clinical significance and do not require treatment, with resolution occurring by weeks to four months of age. They may present a challenge for clinicians because they can become infected, requiring drainage and antibiotic therapy $[83,84]$.

On cross-sectional imaging, acute cephalohematomas are crescent-shaped collections adjacent to the outer table of the skull. Chronic cephalohematomas may calcify and appear hyperdense on CT $[82,83]$. Evolutionary changes of cephalohematoma may demonstrate erosive changes and periosteal reaction that can be worrisome in the absence of a clinical history. MRI signal intensity follows that of subacute haemorrhage but may change with the stage of haemorrhage.

\section{Infection}

\section{Osteomyelitis}

Skull osteomyelitis in the paediatric population is most commonly a complication of a skull wound following either surgery or trauma. It may also occur secondary to sinus or ear infection, at the level of the frontal and parietotemporal bones, respectively. In addition, it may result from a complication of an infected scalp wound from the use of forceps or be secondary to intrauterine monitoring (Figure 16A). 

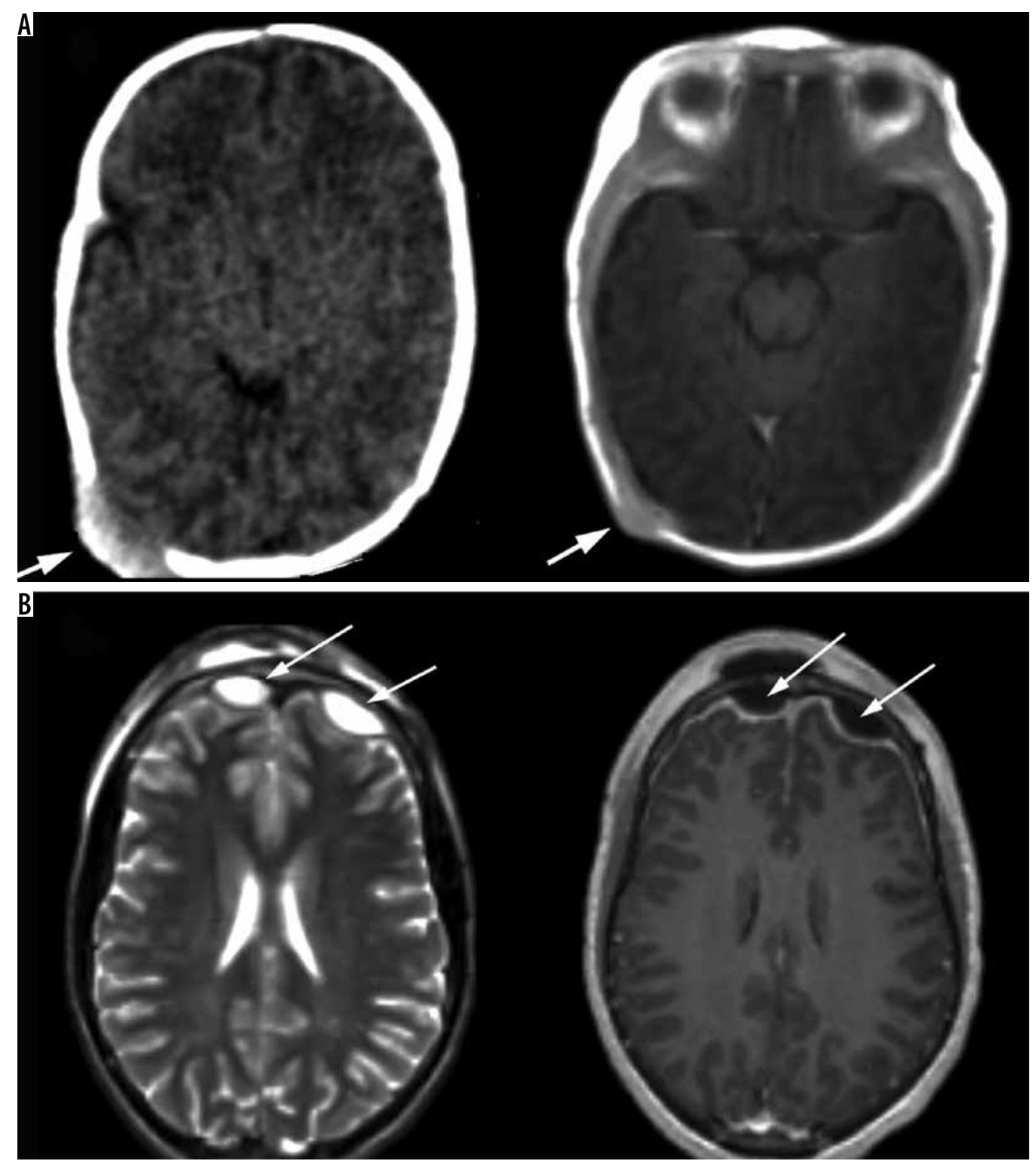

Figure 16. A) Two-month-old baby boy with MRSA osteomyelitis of skull and scalp abscess. Left: Axial head computed tomography shows a mixed hyperdense lesion overlying and expanding the right lambdoid suture. Right: Post Gd T1-W image shows enhancing soft tissue with intracranial extension and dural thickening/enhancement (black arrow). B) 16-year-old male with acute sinusitis and Pott's puffy tumour. Left: axial T2-W and right: Gd-enhanced T1-W images demonstrate peripherally enhancing subgaleal abscess collections with soft tissue swelling and rim-enhancing bifrontal epidural abscesses (white arrow) with associated dural thickening and enhancement

\section{Subperiosteal abscess}

Pott puffy tumour represents a subperiosteal abscess of the frontal bone with frontal osteomyelitis. The infection can spread directly through the thin bone wall of the sinus or through the network of small veins that drain its mucosa (Figure 16B) [85]. Frontal sinusitis and trauma are the most common causes of this condition. The most common causal organisms are streptococci, staphylococci, and anaerobic bacteria $[85,86]$.

Contrast-enhanced CT or MR imaging is needed to evaluate for possible intracranial complications such as epidural/subdural empyema, meningitis, intraparenchymal abscess, and dural venous sinus thrombosis. Subtle intracranial involvement is more easily seen in MR im- aging. In the scalp, rim enhancement may be noted when an organised fluid collection is present. Surgical drainage remains the mainstay of therapy.

\section{Benign neoplasia}

\section{Osteoma}

Osteomas are uncommon in children, but the most common benign bony tumour in adults [87]. Skull lesions often present as a painless lump, while paranasal sinus lesions present with sinusitis or exophthalmos. Conventional radiographs demonstrate a well-circumscribed hyperostotic lesion (Figure 17A), which can be further characterised by CT (Figure 17B-D). Multiple lesions 

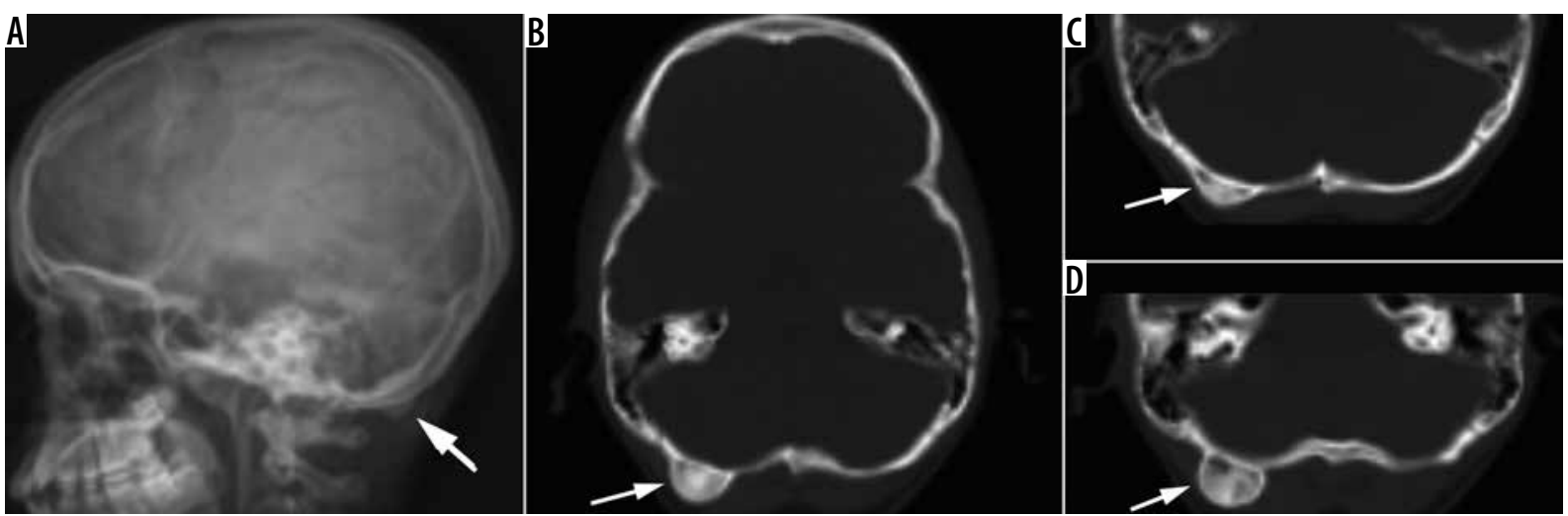

Figure 17. Thirteen-year-old male patient with osteoma of the right occipital bone. A) Lateral projection X-ray of the skull shows a well-defined focal bulging mass at the level of the occipital bone (white arrow) seen as an ovoid dense sclerotic lesion related to the outer table of the right occipital bone on the axial head computed tomography images (B-D)
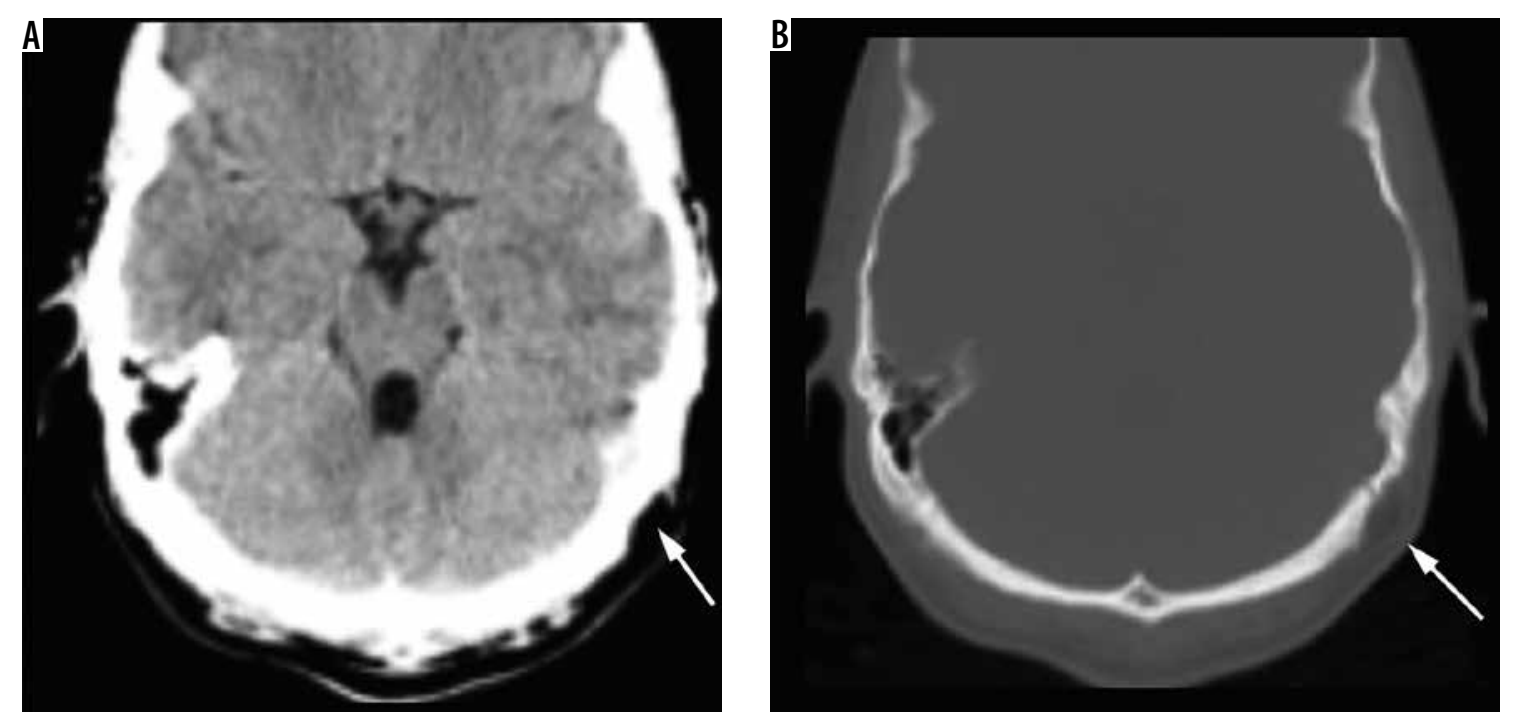

Figure 18. A, B) Axial non-contrast computed tomography of the head in the soft tissue and bone window shows the presence of a small homogenous lesion of fat density overlying the left occipital bone

are seen in Gardner's syndrome or hereditary polyposis syndrome. Prognosis is excellent with local resection. The differential diagnosis includes fibrous dysplasia and sessile osteochondroma.

\section{Lipoma}

Lipomas are benign tumours consisting of mature fat cells. They are well-demarcated masses of fat density (CT) and signal (MRI), with drop of signal on fat-saturated sequences (Figure 18). The presence of soft tissue enhancement should raise concern for liposarcoma. The differential diagnosis of fat-containing lesions of the skull includes primarily dermoid and teratoma.

\section{Myofibroma}

Infantile myofibromatosis is a rare mesenchymal disorder of childhood, defined by the presence of tumours in the muscle, skin, bone, viscera, and subcutaneous tissue [88-90]. It represents the most common fibrous tumour of infan- cy [91]. The disease is divided into two groups: solitary, which is the most common, and multicentric.

On imaging, bone lesions are round, $1-3 \mathrm{~cm}$ in size, well-defined lytic areas with or without a sclerotic rim [91-94], and they most commonly involve the temporal and parietal bones $[95,96]$. On CT, the lesions appear hypodense or isodense to the brain, and enhancement may be marked and homogeneous or heterogeneous [95]. On MRI, they are hypointense/isointense on T1-, and hyperintense or isointense on T2-weighted images, with marked enhancement after contrast administration (Figure 19). The differential diagnosis of a similar-looking calvarial lesion includes Langerhans cell histiocytosis, osteomyelitis, metastasis, osteoblastoma, epidermoid cyst, haemangioma, fibrous dysplasia, fibrosarcoma, and intraosseous meningioma [92,96-100].

\section{Intraosseous haemangioma}

Intraosseous haemangiomas constitute $1-5 \%$ of calvarial neoplasms in the paediatric population $[101,102]$. Two 

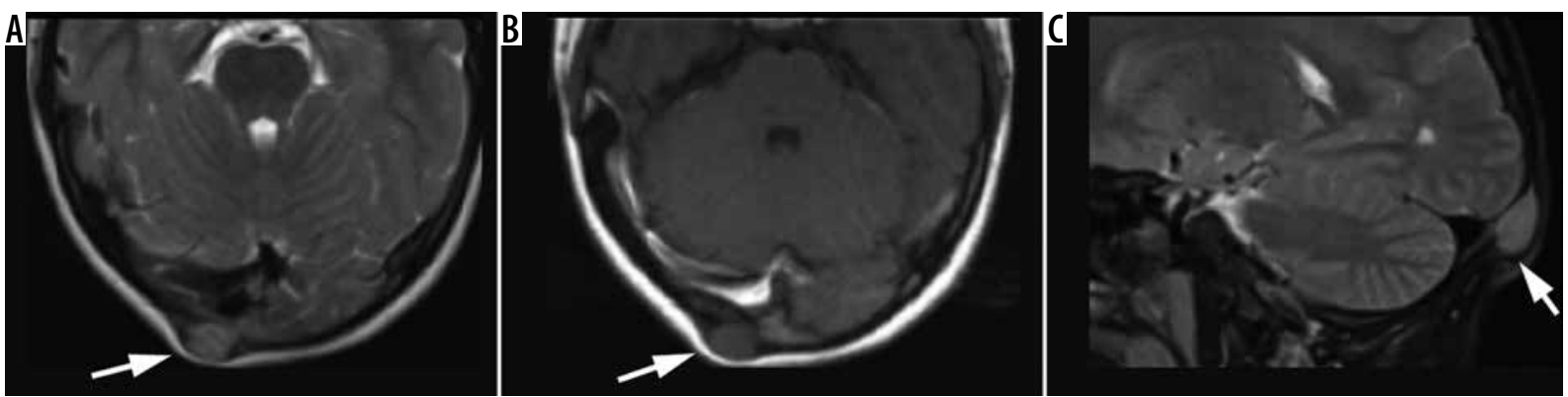

Figure 19. A) Axial T2-W, B) Post-Gd T1-W, and (C) sagittal fat-suppressed T2 images show a right occipital subgaleal mass (arrows) with isointense T2 signal and no contrast enhancement. Pathological proven scalp myofibroma
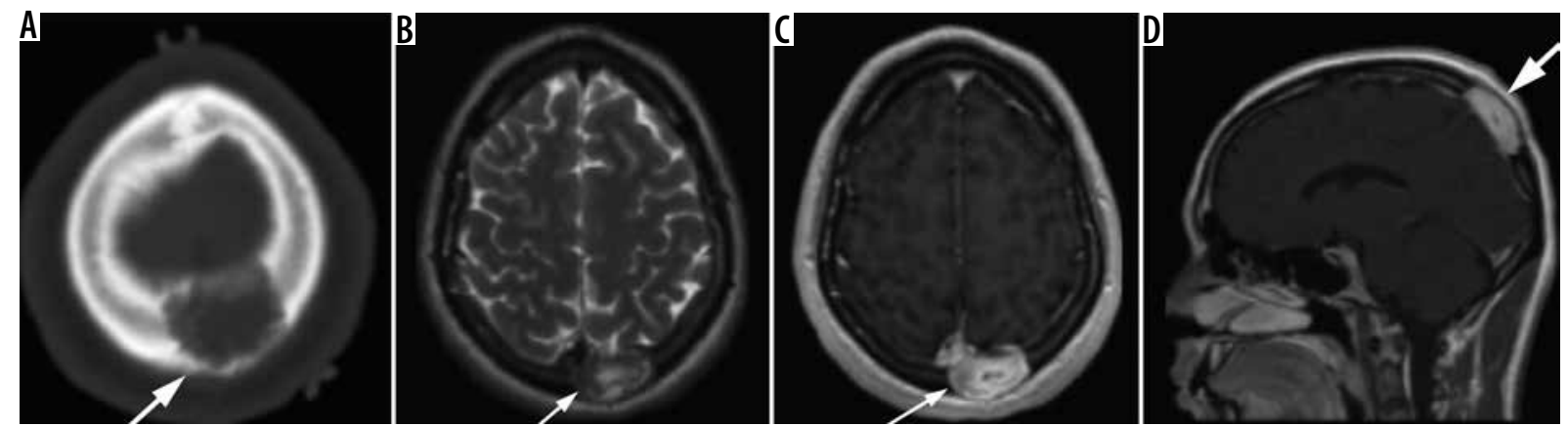

Figure 20. Eighteen-year-old male patient with intraosseous haemangioma. A) Axial head computed tomography shows a well-defined osteolytic lesion with a characteristic sunburst pattern at the vertex. B-D) Axial T2 and axial and sagittal T1 gadolinium enhanced images shows predominantly high T2 signal intensity lesion showing diffuse homogenous enhancement at the level of the left parietal bone

forms exist: an uncommon globular form occurring at the skull base, and a more frequent sessile form, within the calvarium [103]. The globular subset more often have intracranial extension, which may result in neurological symptoms.

Computed tomography and conventional radiographic imaging typically demonstrate a well-defined osteolytic lesion involving the diploic space expanding the outer table with a sunburst or honeycomb trabecular pattern. Periosteal reaction is rare [104]. MRI can depict the vascular channels and can clearly define the extent of the lesion and its relationship to adjacent neurovascular structures (Figure 20) [105]. After contrast administration, haemangiomas show diffuse and heterogeneous enhancement [106]. Occasionally, a haemangioma may become aggressive, with an intra- or extracranial soft-tissue component that may simulate a malignant neoplasm $[106,107]$.

\section{Infantile haemangioma}

Infantile haemangioma is the commonest vascular neoplasm of infancy, with a prevalence of about $2-3 \%$ and a female predominance [108-111]. They are most commonly located in the face and neck (60\% of cases), followed by the trunk (25\%) and extremities (15\%) $[108,110,112]$. They are usually not visible at birth but show rapid growth during the first few weeks, becoming evident by three months of age. No treatment is required because of spontaneous involution; however, treatment may be needed if the haemangioma is symptomatic or oc- curs in regions where there is secondary loss of function or aesthetic impairment.

The diagnosis is made clinically; however, imaging, specifically MRI, may be required in deep haemangiomas with normal overlying skin, when evaluation of extension is necessary for therapeutic planning.

MR imaging features change with the different evolutionary stages. During the proliferative phase, they are well-delineated lesions with high signal on T2- and isointense signal on T1-weighted images, with early avid enhancement and presence of flow-voids (Figure 21) [108]. Perilesional oedema should not be seen [113]. The feature distinguishing an infantile haemangioma from an AVM is the absence of arteriovenous shunting [114]. During the involuting phase, increasing amounts of fat replace the tumour, seen as foci of increased signal intensity on T1-weighted images with a decrease in the degree of enhancement [108]. If perilesional oedema is present, other tumoural lesions (sarcoma, neuroblastoma, haemangiopericytoma, fibrosarcoma, rhabdomyosarcoma) must be ruled out [113].

\section{Malignant neoplasia}

\section{Langerhans cell histiocytosis}

Histiocytosis is characterised by the proliferation of Langerhans cells, a type of histiocyte from the monocyte-macrophage cell line [115]. Langerhans cell histiocytosis (LCH) 

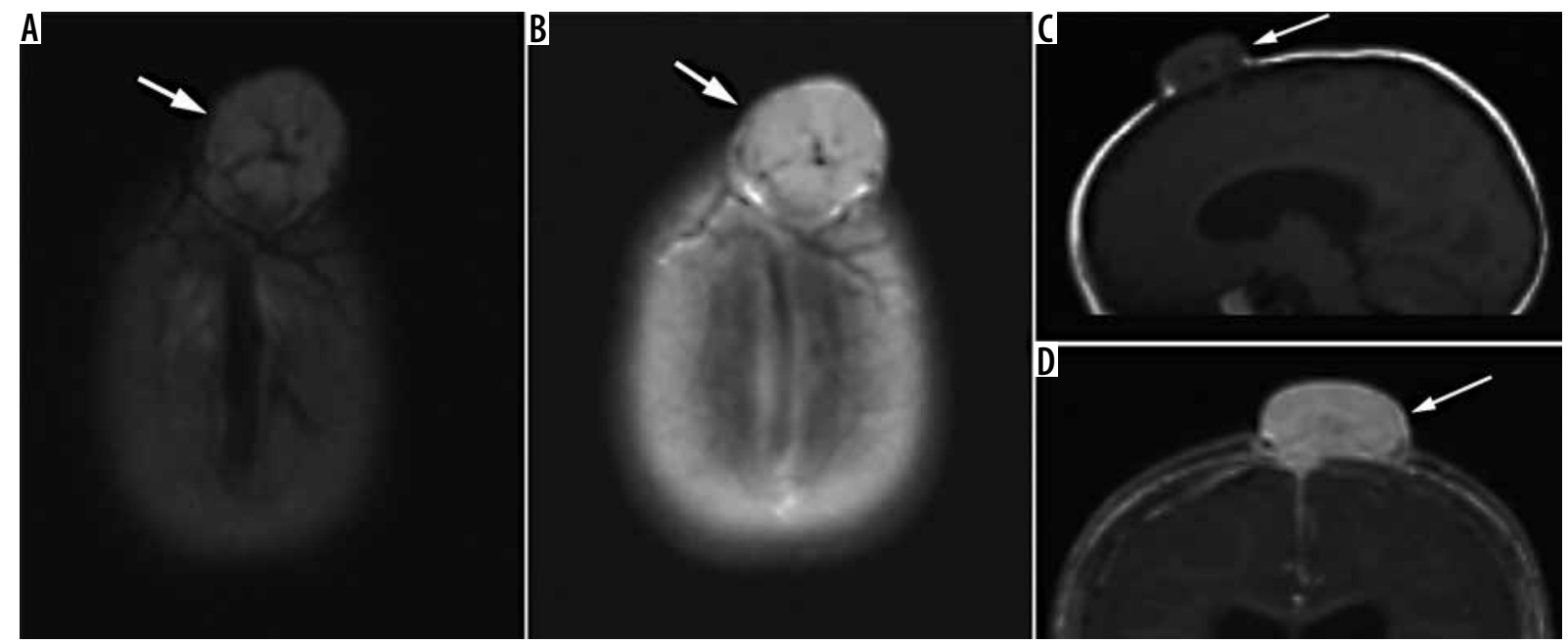

Figure 21. Eleven-month-old boy with infantile haemangioma. A) Sagittal T1-W, B) axial T2-W, post-Gd (C) axial, and (D) coronal T1-W images show a $\mathrm{T} 2$ hyperintense and avidly enhancing lesion arising from the frontal calvarium with central flow voids
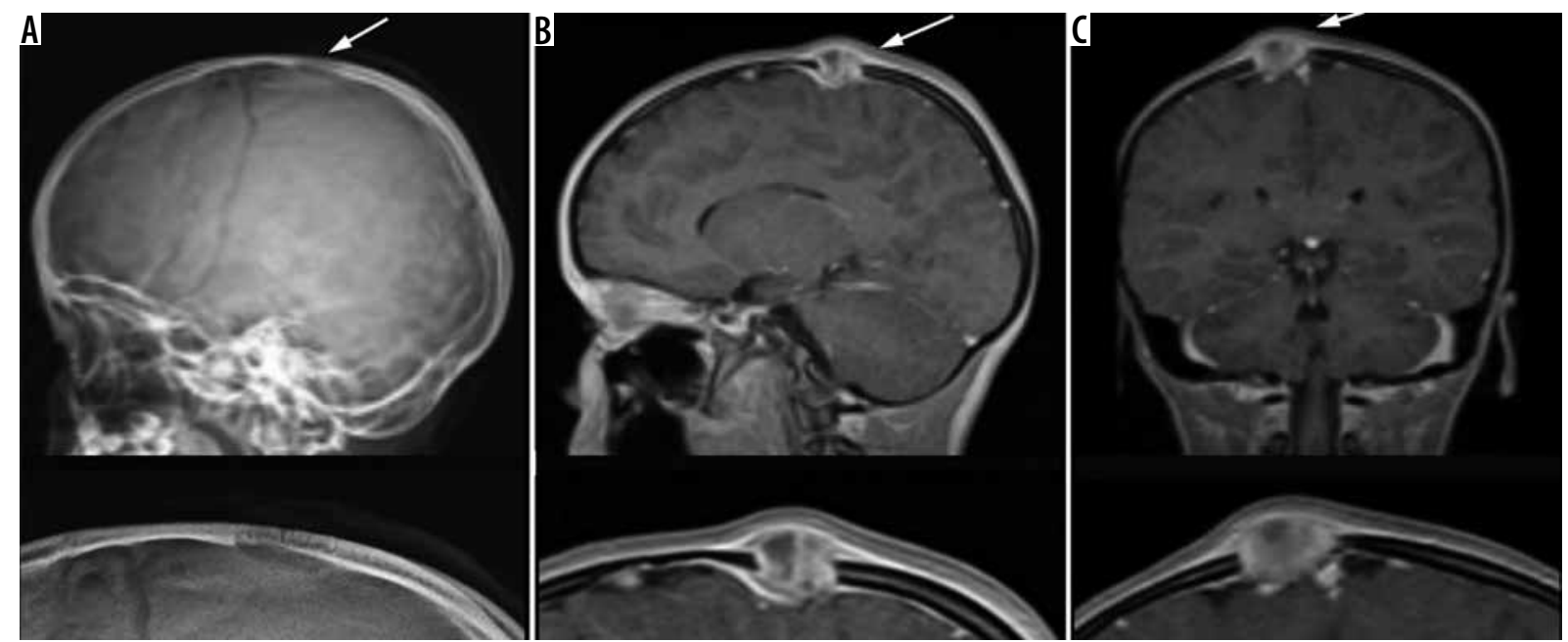

Figure 22. Seven-year-old boy with Langerhans cell histiocytosis. A) Lateral skull plain radiograph shows a single sharply marginated (bevelled edges) lytic calvarial lesion. Subsequent magnetic resonance imaging. B, C) Pre- and post-Gd T1-WIs show a heterogeneously enhancing intradiploic calvarial mass extending across the inner and outer tables

is subdivided into three types based on the organs involved, patient's age at onset, and clinical course: localised, chronic disseminated, and fulminant-disseminated. Localised LCH is the mildest and most common form and involves either bone or lung, with a peak prevalence between one and four years of age and a slight male predilection [116]. Localised lesions in this age present as painful lumps and are usually clinically misdiagnosed as trauma or infection [117]. Head and neck manifestations of LCH occur in the majority of children, with the skull and skin frequently involved [117120]. The calvaria is the most common location of osseous LCH [121]. Other commonly involved sites include the orbit, maxilla, mandible, and temporal bone [122].

At radiography, bone lesions appear lytic, with either a well- or poorly-defined border without reactive sclerosis or periosteal reaction, and they are described as "punched-out" lesions [123]. Skull lesions typically have a bevelled-edge appearance due to asymmetric destruction of the inner and outer tables. On CT, they present as an enhancing soft-tissue mass with bone erosion. On MRI, they have low to isointense signal intensity on T1- and hyperintense signal on T2-weighted images with diffuse enhancement post contrast administration (Figure 22)[122]. Both CT and MRI are often required for follow-up of repair of bone-destructive lesions and resolution of soft-tissue masses. Intracranial involvement is best seen with MR imaging.

\section{Osteosarcoma}

Osteosarcoma is the most common malignant tumour of bone, but it rarely occurs in the skull [124]. The mandible is the most common craniofacial bone affected. It may result from malignant degeneration of fibrous dysplasia. The tumours increase in size rapidly and commonly present with pain and swelling. Gross total excision is thought to be the best treatment. 

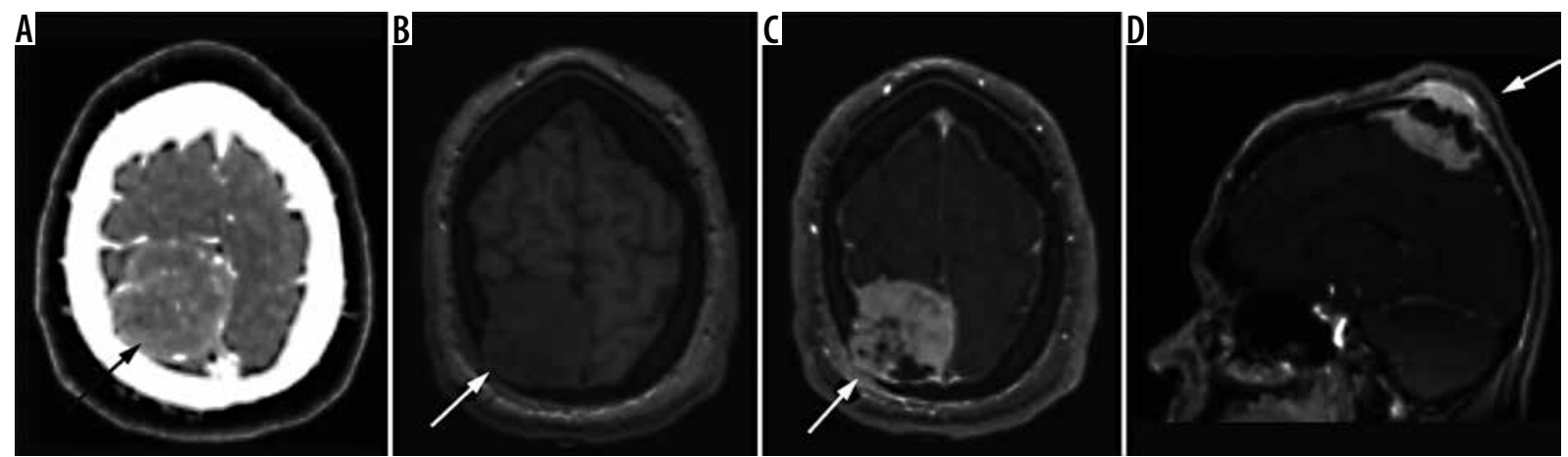

Figure 23. Eighteen-year-old male with right parietal osteosarcoma. A) Contrast-enhanced head computed tomography shows a right parietal enhancing mass. B) Axial T1-W and (C, D) post-Gd T1-W images show an intensely enhancing extra-axial mass with extracranial (white arrows) and intracranial, extra-axial components. Central non-enhancing area is consistent with necrosis
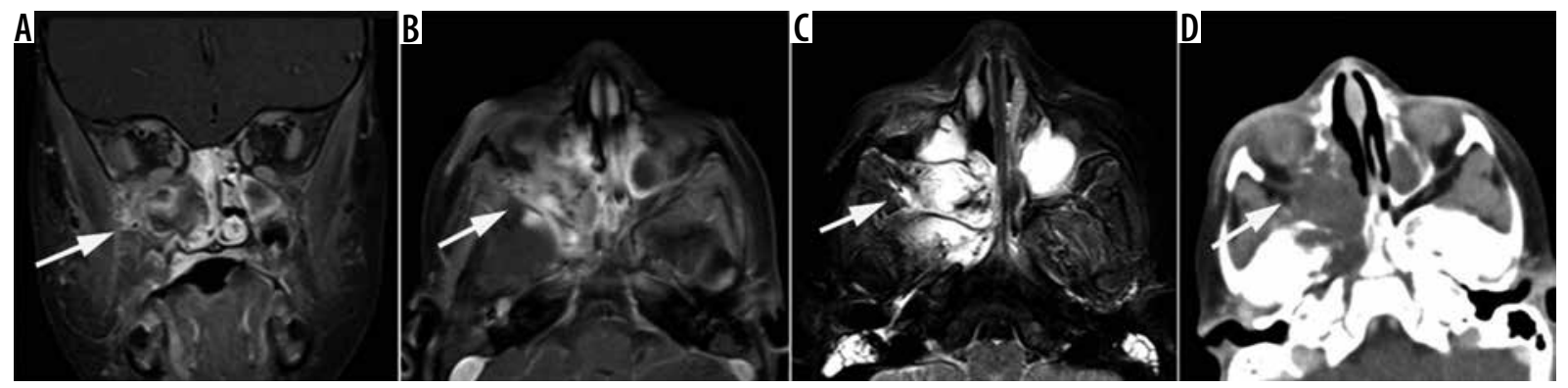

Figure 24. Three-month-old girl with right sinonasal embryonal rhabdomyosarcoma. A-C) Coronal and axial T1 fat-sat post-contrast and axial T2 fat sat images of the face, respectively, shows a heterogeneously enhancing mass centred at the level of the right maxillary sinus extending to the nasal cavity and masticator space with bone destruction as demonstrated on axial computed tomography post-contrast image of the face (D)

MRI and CT show bone growth with lytic areas and periosteal remodelling (Figure 23). No radiographic finding is pathognomonic. Biopsy is required for definitive diagnosis.

\section{Rhabdomyosarcoma}

Rhabdomyosarcoma is the commonest soft tissue sarcoma in children [125]. The head and neck are the most common locations, particularly the anterior skull base (40\%) and the orbit (25\%) [125]. Symptomatology depends on tumour size and location. Imaging findings are non-specific and may be confused with other tumours. MRI is the technique of choice due to excellent soft tissue contrast and is primarily used to assess disease extension and aid in staging. It usually demonstrates heterogeneously enhancing soft tissue mass with bone destruction and bone remodelling (Figure 24).

\section{Metastatic neuroblastoma}

Neuroblastoma is the third most common malignancy in children, preceded by leukaemia and primary brain tumours. They arise most commonly in the adrenal gland or less often along the sympathetic chain in the abdomen. Neuroblastomas are metastatic in up to $70 \%$ of patients at the time of presentation [126]. Metastatic cranial manifestations most often present as osseous lesions involving the calvaria, orbit, or skull base [127], with neuroblastoma being the commonest metastasis to the skull in this age group [128].

At imaging, metastatic lesions of the skull produce several radiographic findings: thickened bone, the socalled "hair-on-end" periosteal reaction, lytic defects, and separation of sutures. The differential diagnosis of multiple lytic skull lesions in a child includes Langerhans cell histiocytosis, leukaemia, lymphoma, and sarcoma metastases $[127,129]$. Neuroblastoma has a predilection to metastasise to the dura and tends to favour the external surface of the dura (Figure 25). The dura acts as a defence mechanism to direct invasion, with intraparenchymal extension rarely seen [126]. Neuroblastoma often metastasises to the skull base and orbits in the late stages of the disease. Both LCH and metastatic neuroblastoma can involve the posterolateral part of the orbit [130].

\section{Metastatic Ewing's sarcoma}

Ewing's sarcoma (ES) is the second most common primary bone malignancy in children [131]. It can develop in any bone or tissue, but the most common location is long or flat bones. Primary ES of the skull is rare, with metastasis to the skull being more common [132]. The clinical presentation is usually pain and swelling. The imaging appearance of these tumours is very variable, but they are usually poorly marginated, with an aggressive appearance and extension into adjacent soft tissues. They show intense and heterogeneous enhancement (Figure 26). 

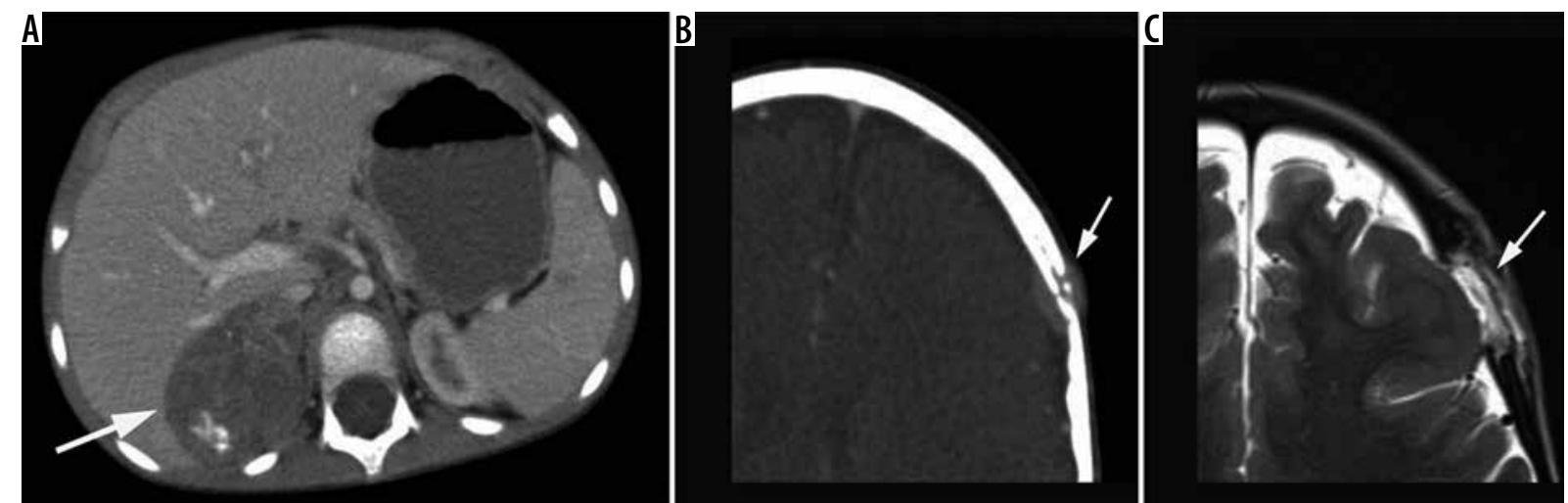

Figure 25. Five-year-old girl with stage IV metastatic neuroblastoma to the calvarium. A) Axial contrast-enhanced computed tomography (CT) of the abdomen shows a bulky and partially-calcified right adrenal neuroblastoma. B) Axial head (T on bone window shows a destructive lesion within the diploic space in the left frontal calvarium with soft tissue components (arrow). C) Axial T2-W image shows corresponding full thickness skull defect and hyperintense signal
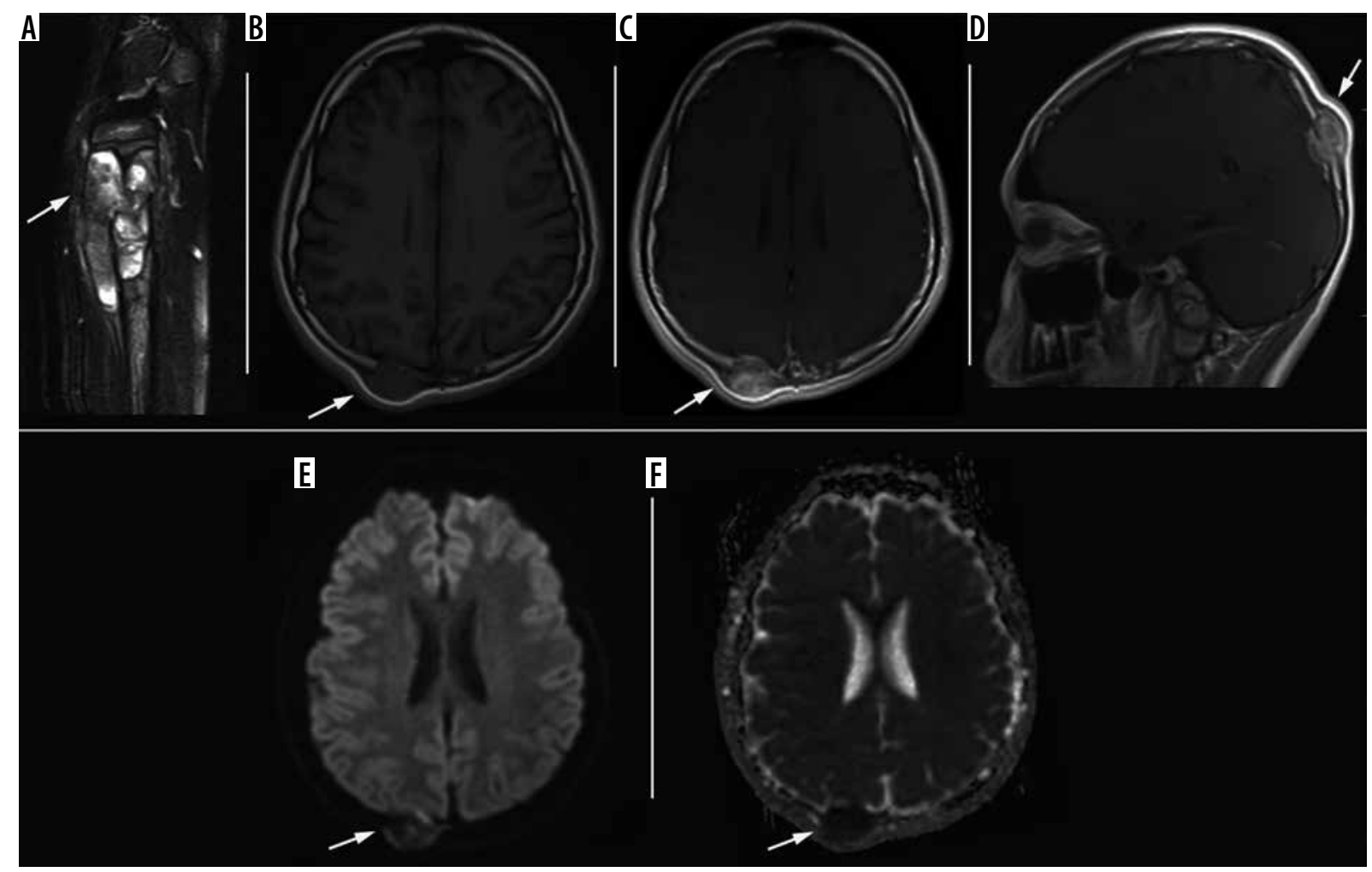

Figure 26. Calvarial metastasis in a 15-year-old boy with history of Ewing's sarcoma of the left distal ulna. A) Sagittal STIR of the left forearm shows the heterogeneously hyperintense primary tumour of distal ulna with associated soft tissue involvement. B, C) Pre- and post-Gd T1-WI demonstrate a destructive calvarial metastasis with heterogeneously iso/hypointense FLAIR signal and avid gadolinium enhancement. D) Sagittal Gd-enhanced T1-WI shows avid enhancement. E, F) Axial DWI and ADC map shows mild true diffusion restriction

\section{Vascular}

\section{Venous lakes}

Transcalvarial venous channels consist of holes in the calvarium through which emissary veins pass, connecting the dural venous sinuses with veins external to the skull. They usually present as serpiginous or linear lucencies with sclerotic borders through the skull and are sometimes confounded with fractures or sutures [133]. When these veins are enlarged, they are known as venous lakes.
On CT imaging, they appear as round or oval lucent foci at the level of the inner table of the skull [134]. These show high signal on T2-weighted images and intermediate or low signal on T1-weighted images with marked enhancement after contrast administration (Figure 27).

\section{Venous malformation}

Venous malformations consist of a wide range of congenital lesions which are clinically characterised by a soft and non-pulsatile bluish mass, occurring in the head and neck in $40 \%$ of cases [135]. 


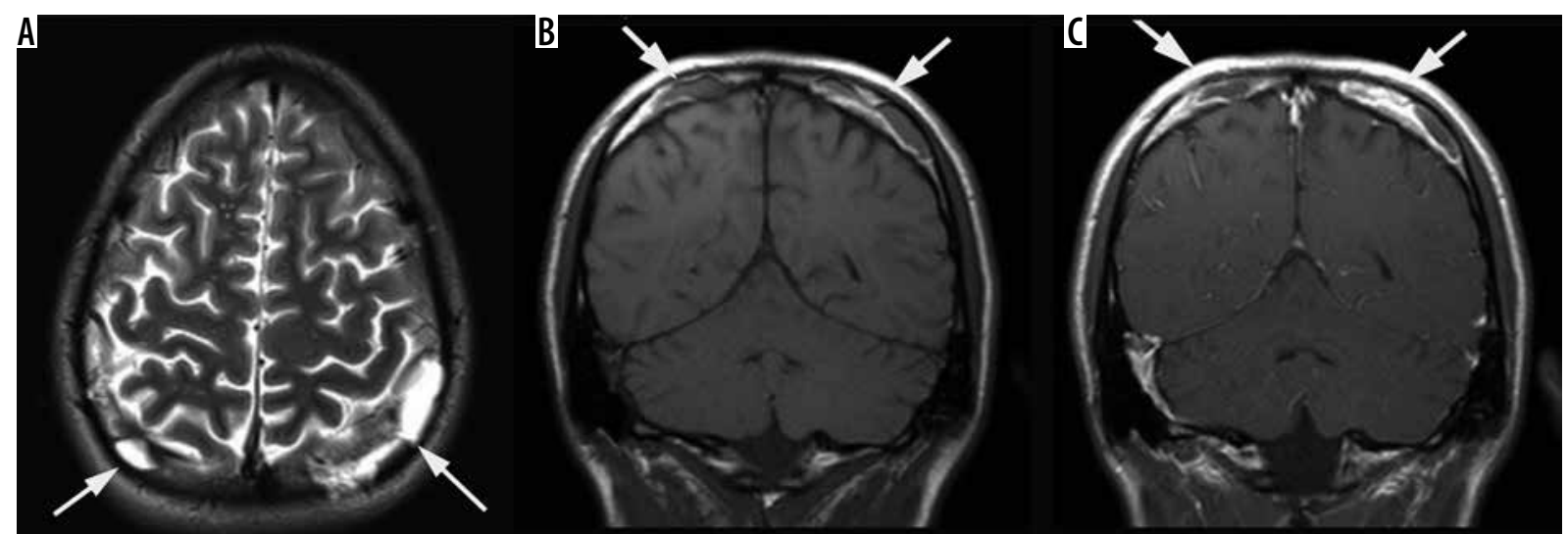

Figure 27. Seventeen-year-old boy with multiple venous lakes. A) Axial T2-W show multiple hyperintense lesions (arrows) involving the diploic spaces of the calvarium. B, C) Pre- and post-Gd-enhanced T1-W images show peripheral delayed enhancement
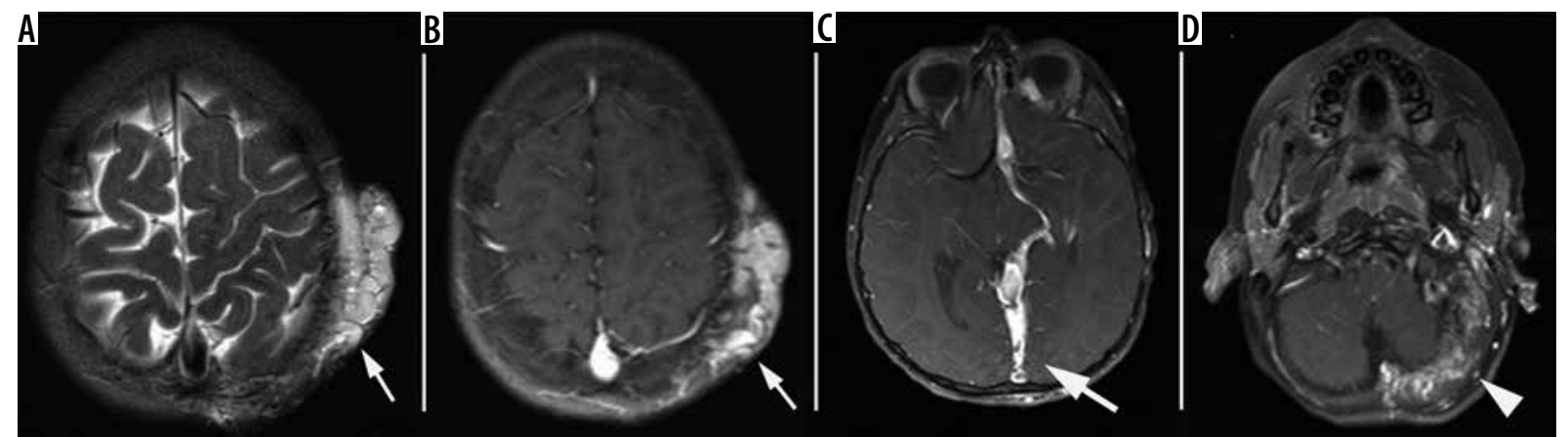

Figure 28. Ten-year-old boy with large left parieto-occipital venous malformation with intracranial developmental venous anomalies. A) Axial T2-W and (B-D) post-Gd T1-W images show mixed T2 high signal lesion with corresponding intense contrast enhancement along left parietal calvarium (arrows in $A$ and $B$ ) extending intracranially at occipital and suboccipital regions (arrowhead). Also noted is an associated complex intracranial developmental venous malformation with enlarged veins (arrow in C)

Magnetic resonance imaging is the best modality to define lesion size and extent. They are often hyperintense on T2-weighted sequence, with internal septation and variable enhancement (Figure 28). Phleboliths, appearing as focal signal voids, are a specific characteristic [136]. As a low-flow lesion, flow voids seen with proliferating haemangiomas or high-flow arteriovenous malformations are not identified in venous malformations. Treatment typically involves some combination of sclerotherapy and surgical removal [135].

\section{Post-operative}

\section{Post-operative intraosseous pseudomeningocele}

Intradiploic pseudomeningocele are very rare post-operative or post-traumatic complications in paediatric patients [137-139]. They are characterised by a breach of the inner table with a tear of dura mater, with intradiploic accumulation of CSF in a sac with a covering lined by arachnoid membrane. The time interval between trauma and diagnosis of post-traumatic intradiploic pseudomeningocele is variable, ranging from 10 months to 50 years [140-142], with the occipital region being the most common location.

On plain radiograph of the skull, they appear as an eggshell expansion of the diploic space with intact outer table.
A CT scan best defines the extent of the bony defect and intactness of the outer table, with three-dimensional reconstruction aiding in surgical planning (Figure 29). MRI is the modality of choice and helps in the diagnosis by excluding dermoid and epidermoid cysts [141]. They typically have signal intensities similar to CSF. The differential diagnosis includes leptomeningeal cysts (Figure 30), which result from diastatic fractures causing laceration of dura mater as well as the inner and outer tables [143-145].

\section{Conclusions}

Paediatric skull lesions often represent a diagnostic challenge to radiologists. However, if an appropriate imaging and clinically based approach is used, a definitive diagnosis is possible in the majority of cases. These lesions range from congenital, traumatic, infectious, and neoplastic to vascular. Many features of these lesions are important in management and may be discovered with proper imaging. A variety of cross-sectional imaging methods are now available that help characterise these lesions and guide therapy.

\section{Conflict of interest}

The authors declare no conflict of interest. 

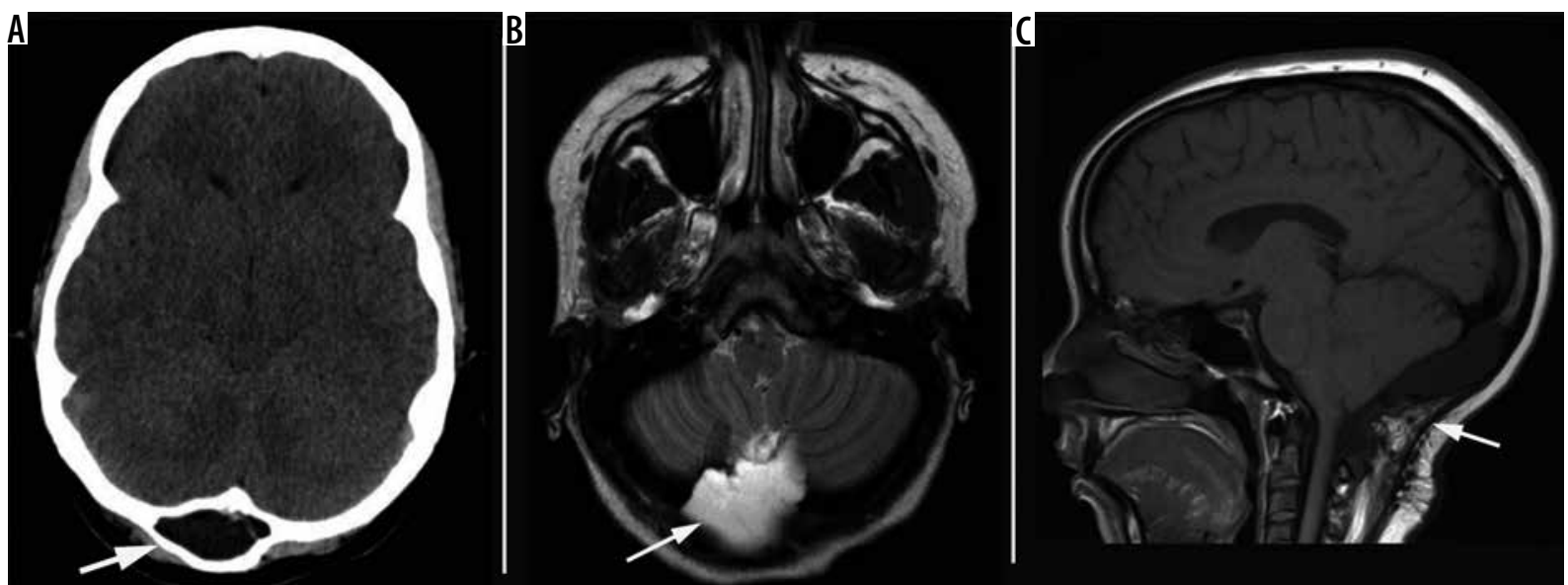

Figure 29. Fifteen-year-old girl with Chiari malformation, status post suboccipital craniectomy for decompression and a post-op intraosseous pseudomeningocele. A) Axial head computed tomography shows an expansile fluid density intraosseous lesion separating the inner and outer table of the occipital calvarium. B) Axial T2-WI shows a suboccipital pseudomeningocele with cerebrospinal fluid signal and intraosseous extension. C) (oronal T1-W image shows changes of suboccipital craniectomy and pseudomeningocele (arrows)
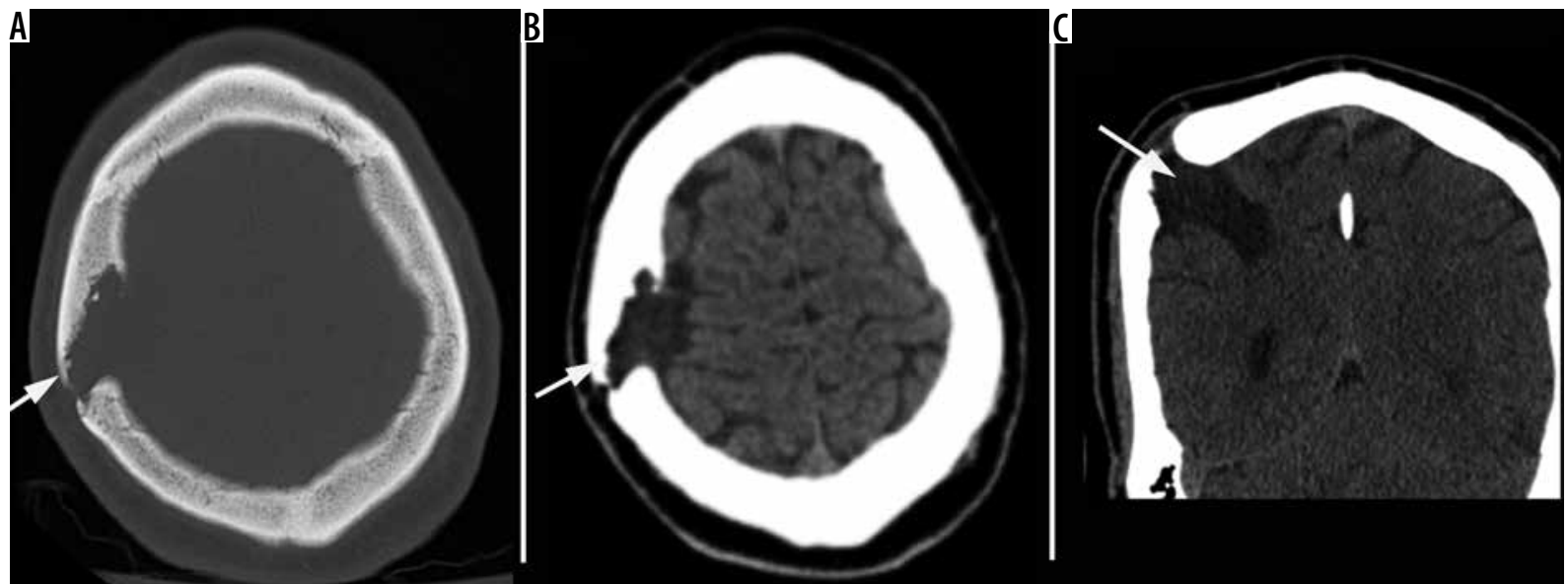

Figure 30. Companion case in an adult patient with history of prior trauma. A, B) Axial computed tomography (CT) images on bone and parenchyma windows show focal encephalomalacia of right frontoparietal lobe with cerebrospinal fluid (CSF) extending and expanding the right parietal bone fracture. Note the scalloping of the fracture margins. C) Coronal (T image shows the extent of encephalomalacia and extension of (SF through the skull defect

\section{References}

1. Dupuis O, Silveira R, Dupont C, et al. Comparison of “instrument associated" and "spontaneous" obstetric depressed skull fractures in a cohort of 68 neonates. Am J Obstet Gyencol 2005; 192: 165-170.

2. Guha-Ray DK. Intrauterine spontaneous depression of fetal skull: a case report and review of literature. J Reprod Med 1976; 16: 321-324.

3. Tavares LA, Kottamasu SR, Ezhuthacha SG, et al. Neonatal skull depression: review of four cases. J Perinatol 1989; 9: 423-426.

4. Tibbs RE, Lee DC, Parent AD. Depressed skull fracture. In: Batjer HH, Loftus CM (eds.). Textbook of Neurological Surgery: Principles and Practice. Lippincott Williams and Wilkins, Philadelphia 2003; 1082-1095.

5. Sunil K, Agrawal DM, Praveen Kumar DM, et al. Congenital depression of the skull in neonate: a case of successful conservative management. J Child Neurol 2010; 25: 387-389.

6. Tovar-Spinoza S, Kim P. Congenital depressed skull fracture in the absence of trauma: case report and literature review. Dove Press J 2012; $2: 11-14$
7. Vidal Mico S, Lopez Navarro M, Téllez de Meneses M, et al. Spontaneous resolution of a congenital depressed skull fracture. An Esp Pediatr 2004; 54: 78-80.

8. Axton J, Levy L. Congenital moulding depressions of the skull. Br Med J 1965; 1: 1644-1647.

9. Saunders B, Lazoritz S, McArtor R, et al. Depressed skull fracture in the neonate. J Neurosurg 1979; 50: 512-514.

10. Eisenberg D, Kirchner S, Perrin E. Neonatal skull depression unassociated with birth trauma. AJR Am J Roentgenol 1984; 143: 1063-1064.

11. Doumouchtosis SK, Arulkamaran S. Head injuries after instrumental vaginal deliveries. Curr Opin Obstet Gynecol 2006; 18: 129-134.

12. Beyers N, Moosa A, Bryce RL, et al. Depressed skull fracture in the newborn. S Afr Med J 1978; 54: 830-832.

13. Hanlon L, Hogan B, Corcoran D, Ryan S. Congenital depression of the neonatal skull: a self limiting condition. Arch Dis Child Fetal Neonatal Ed 2006; 91: F272. 
14. Shamsian N, Robertson A, Anslow P. Congenital skull indentation: a case report and review of the literature. BMJ Case Reports 2012; 2012: pii: bcr20126157.

15. Lenyoun EH, Lampert JA, Xipoleas GD, Taub PJ. Salvage of calvarial bone graft using acellular dermal matrix in nasal reconstruction and secondary rhinoplasty for frontonasal dysplasia. J Craniofac Surg 2011; 22: 1378-1382.

16. Wu E, Vargevik K, Slavotinek AM. Subtypes of frontonasal dysplasia are useful in determining clinical prognosis. Am J Med Genet A 2007; 143A: 3069-3078.

17. Fryburg JS, Persing JA, Lin KY. Frontonasal dysplasia in two successive generations. Am J Med Genet 1993; 46: 712-714.

18. Vaccarella F, Pini Prato A, Fasciolo A, et al. Phenotypic variability of Pai syndrome: report of two patients and review of the literature. Int J Oral Maxillofac Surg 2008; 37: 1059-1064.

19. Fearon JA. Rare craniofacial 2008 clefts: a surgical classification. J Craniofac Surg 2008; 19: 110-112.

20. Pham NS, Rafii A, Liu J, et al. Clinical and genetic characterization of frontorhiny: report of 3 novel cases and discussion of the surgical management. Arch Facial Plast Surg 2011; 13: 415-420.

21. Gaball CW, Yencha MW, Kosnik S. Frontonasal dysplasia. Otolaryngol Head Neck Surg 2005; 133: 637-638.

22. Martinelli P, Russo R, Agangi A, Paladini D. Prenatal ultrasound diagnosis of frontonasal dysplasia. Prenat Diagn 2002; 22: 375-379.

23. Posnick JC, Seagle MB, Armstrong D. Nasal reconstruction with full-thickness cranial bone grafts and rigid internal skeleton fixation through a coronal incision. Plast Reconstr Surg 1990; 86: 894-902.

24. Frieden IJ. Aplasia curls congenita: a clinical review and proposal for classification. Acad Dermatol 1986; 114: 646-660.

25. Sybert VP. Aplasia cutis congenita: a report of 12 new families and review of the literature. Pediatric Dermatol 1985; 3: 1-14.

26. Croce EL Purohit RC, Janovski NA. Congenital absence of the skin (aplasia cutis congenita). Arch Surg 1973; 106: 732-734.

27. Wolpow ER, Schaumberg HH. Structure of the human arachnoid granulation. J Neurosurg 1972; 37: 724-727.

28. Abbott R, Cutting CB, Wisoff JI-I, et al. Aplasia cutis congenita of the scalp: issues in its management. Pediatr Neurosurg 1991-1992; 17: 182-184.

29. Schneider BM, Berg RA, Kaplan AM. Aplasia cutis congenita complicated by sagittal sinus hemorrhage. Pediatrics 1980; 66: 948-950.

30. Wexler A, Harris M, Lesavoy M. Conservative treatment of cutis aplasia. Plast Reconstr Surg 1990; 86: 1066-1071.

31. Vinocur CD, Weintraub WH, Wilensky RJ. Surgical management of aplasia cutis congenita. Arch Surg 1976; 111: 1160-1164.

32. Demmel U. Clinical aspects of congenital skin defects: I. Congenital skin defects on the head of the newborn. II. Congenital skin defects on the trunk and extremities of the newborn. III. Causal and formal genesis of congenital skin defects of the newborn. Eur J Pediatr 1975; 121: 21-50.

33. O'Brien BM, Drake JE. Congenital defects of skull and scalp. Br J Plast Surg 1960; 13: 102-109.

34. Kosnik EJ, Sayers MP. Congenital scalp defects: aplasia cutis congenita. J Neurosurg 1975; 42: 32-36.

35. Broomhead IW. Congenital defects of the scalp. In Mustard JC, Jackson IT (eds.). Plastic surgery in infancy and childhood. 3rd ed. Churchill Livingstone, New York 1988; 451-454.
36. Muakassa KF, King RB, Stark DB. Neurosurgical approach to congenital scalp and skull defects. J Neurosurg 1982; 56: 711-715.

37. Aknin J, Seguin R Brunon J, Oulhchane M. Skin aplasia of the vertex. Report of a familial form. Rev Stomatol Chit Maxillofac 1992; 93: 267-272.

38. Spear SL, Mickle JP. Simultaneous cutis aplasia congenita of the scalp and cranial stenosis. Plast Reconstr Surg 1983; 71: 413-417.

39. Arand AG, Ball WS, Crone KR. Congenital scalp defects: AdamsOliver syndrome. Pediatr Neurosurg 1991-1992; 17: 203-207.

40. Pozzati E, Padovanie R, Frank F, Gaist G. Leptomeningeal angiomatosis and aplasia congenita of the scalp: case report. J Neurosurg 1983; 58: 937-940.

41. Vasconez LO. Congenital defect of the skull and scalp due to an arteriovenous malformation. Plast Reconstr Surg 1973; 51: 692-695.

42. Ktister W, Lenz W, Kiriiinen H, Majewski F. Congenital scalp defects with distal limb anomalies (Adams-Oliver syndrome): report of ten cases and review of the literature. Am J Med Genet 1988; 31: 99-115.

43. Turner L. The structure of arachnoid granulations with observations on their physiologic and pathological significance. Ann R Coll Surg Engl 1961; 29: 237-264.

44. LeGros Clark WE. On the pacchionian bodies. J Anat 1920; 55: 40-48.

45. Key A, Retzius G. Stadien in der Anatomie des Nerven systems und des Bind egenwebes. Norstedt and Soner, Stockholm 1876.

46. Browder J, Kaplan H, Howard J. Hyperplasia of pacchionian granulations. Arch Pathol 1973; 95: 315-317.

47. Krisch B. Ultrastructure of the meninges at the site of penetration of veins through the dura mater, with particular reference to pacchionian granulations: investigations in the rat and two species of New-World monkeys (Cebus apella, Callitrix jacchus). Cell Tissue Res 1988; 251: 621-631.

48. Upton ML, Weller RO. The morphology of cerebrospinal fluid drainage pathways in human arachnoid granulations. J Neurosurg 1985; 63: 867-875.

49. Burger PC, Scheithauer BW, Vogel FS. Intracranial meninges. In: Surgical Pathology of the Brain and its Coverings. $4^{\text {th }}$ ed. Churchill Livingstone, Philadelphia 2002; 89-93.

50. McLendon RE, Tien RD. Tumors and tumor-like lesions of maldevelopmental origin. In: Russell and Rubinstein's Pathology of Tumors of the Nervous System. $6^{\text {th }}$ ed. Oxford University Press, New York 1998; 327-352.

51. Osborn AG. Arachnoid cyst. In: Diagnostic Imaging: Brain. Amirsys, Salt Lake City 2004; I-7-4.

52. Osborn AG. Miscellaneous tumors, cysts, and metastases. In: Diagnostic Neuroradiology. Mosby, St. Louis 1994; 631-649.

53. Rao G, Anderson R, Feldstein NA, Brockmeyer DL. Expansion of arachnoid cysts in children: report of two cases and review of the literature. J Neurosurg 2005; 102 (3 Suppl): 314-317.

54. Falcone C, Tinelli E, Pierallini A, et al. Spontaneous disappearance of juxta-sylvian cyst: MRI study and clinical evaluations. Riv Neuroradiol 2005; 18: 54-58 [In Italian].

55. Naidich TP, Zimmerman RA, Bilaniuk LT. Midface: embryology and congenital lesions. In: Som PM, Curtin HD (eds.). Head and Neck Imaging. $3^{\text {rd }}$ ed. Mosby, St Louis 1996; 3-60.

56. Lowe LH, Booth TN, Joglar JM, Rollins NK. Midface anomalies in children. Radiographics 2000; 20: 907-922. 
57. Annet L, Durez T, Grandin C, et al. Apparent diffusion coefficient measurements within intracranial epidermoid cysts in six patients. Neuroradiology 2002; 44: 326-328.

58. Rahbar R, Shah P, Mulliken JB, et al. The presentation and management of nasal dermoid: a 30-year experience. Arch Otolaryngol Head Neck Surg 2003; 129: 464-471.

59. Fink AM, Maixner W. Enlarged parietal foramina: MR imaging features in the fetus and neonate. AJNR Am J Neuroradiol 2006; 27: 1379-1381.

60. Little BB, Knoll KA, Klein VR, et al. Hereditary cranium bifidum and symmetric parietal foramina are the same entity. Am J Med Genetics 1990; 35: 453-458.

61. Wuyts W, Reardon W, Preis S, et al. Identification of mutations in the MSX2 homeobox gene in families affected with foramina parietalia permagna. Hum Mol Genet 2000; 9: 1251-1255.

62. Valente M, Valente KD, Sugayama SSM, et al. Malformation of cortical and vascular development in one family with parietal foramina determined by an ALX4 homeobox gene mutation. AJNR Am J Neuroradiol 2004; 25: 1836-1839.

63. Barkovich AJ, Vandermarck P, Edwards MS, Cogen PH. Congenital nasal masses: CT and MR imaging features in 16 cases. AJNR Am J Neuroradiol 1991; 12: 105-116.

64. Naidich TP, Zimmerman RA, Bilaniuk LT. Midface: embryology and congenital lesions. In: Som PM, Curtin HD (eds.). Head and Neck Imaging. $3^{\text {rd }}$ ed. Mosby, St Louis 1996; 3-60.

65. Martinez-Lage JF, Poza M, Sola J, et al. The child with a cephalocele: etiology, neuroimaging, and outcome. Childs Nerv Syst 1996; 12: 540-550.

66. Naidich TP, Braffman BH, McLone DG, Zimmerman RA. Cephaloceles and related malformations. AJNR Am J Neuroradiol 1992; 13: 655-690.

67. Mahapatra AK, Suri A. Anterior encephaloceles: a study of 92 cases. Pediatr Neurosurg 2002; 36: 113-118.

68. Barkovich JA. Congenital malformations of the brain and skull. In: Pediatric Neuroimaging. $2^{\text {nd }}$ ed. Raven, New York 1995; 177-275.

69. Hoving EW. Nasal encephaloceles. Childs Nerv Syst 2000; 16: 702-706.

70. Raman Sharma R, Mahapatra AK, Pawar SJ, et al. Trans-sellar transsphenoidal encephaloceles: report of two cases. J Clin Neurosci 2002; 9: 89-92.

71. Lai SY, Kennedy DW, Bolger WE. Sphenoid encephaloceles: disease management and identification of lesions within the lateral recess of the sphenoid sinus. Laryngoscope 2002; 112: 1800-1805.

72. Patterson RJ, Egelhoff JC, Crone KR, Ball WS Jr. Atretic parietal cephaloceles revisited: an enlarging clinical and imaging spectrum? AJNR Am J Neuroradiol 1998; 19: 791-795.

73. Brunelle F, Baraton J, Renier D, et al. Intracranial venous anomalies associated with atretic cephaloceles. Pediatr Radiol 2000; 30: 743-747.

74. Desai V, Priyadarshini SR, Sharma R. Copper Beaten Skull! Can It be a Usual Appearance? Int J Clin Pediatr Dent 2014; 7: 47-49.

75. Virchow R. Uber den Cretinismus, namentlich in Franken, und uber pathologische Schadelformen. Verh Phys Med Gessellschr Wurzbg 1851; 2: 230-271.

76. Derderian C, Seaward J. Syndromic craniosynostosis. Semin Plast Surg 2012; 26: 64-75.

77. Sharma VP, Fenwick AL, Brockop MS, et al. Mutations in TCF12, encoding a basic helix-loop-helix partner of TWIST1, are a frequent cause of coronal craniosynostosis. Nat Genet 2013; 45: 304-307.
78. Reardon WW, Rutland R, Pulleyn P, et al. Mutations in the fibroblast growth factor receptor 2 gene cause Crouzon syndrome. Nat Genet 1994; 8: 98-103.

79. Connolly JP, Gruss J, Seto ML, et al. Progressive postnatal craniosynostosis and increased intracranial pressure. Plastic Reconstr Surg 2004; 113: 1313-1323.

80. Rasmussen SA, Friedman JM. NF1 gene and neurofibromatosis 1. Am J Epidemiol 2000; 151: 33-40.

81. Newton TH, Potts DG. Radiology of the Skull and Brain. C.V. Mosby, St. Louis 1971; 235-608.

82. Kao HC, Huang YC, Lin TY. Infected cephalohematoma associated with sepsis and skull osteomyelitis: report of one case. Am J Perinatol 1999; 16: 459-462.

83. Firlik KS, Adelson PD. Large chronic cephalohematoma without calcification. Pediatr Neurosurg 1999; 30: 39-42.

84. Goodwin MD, Persing JA, Duncan CC, Shin JH. Spontaneously infected cephalohematoma: case report and review of the literature. J Craniofac Surg 2000; 11: 371-375.

85. Verbon A, Husni RN, Gordon SM, et al. Pott's puffy tumor due to Haemophilus influenzae: case report and review. Clin Infect Dis 1996; 23: 1305-1307.

86. Kung SW, Chang DT, Suen PY, et al. Pott's puffy tumour. Hong Kong Med J 2002; 8: 381-382.

87. Shah MV, Haines SJ. Pediatric skull, skull base, and meningeal tumors. Neurosurg Clin N Am 1992; 3: 893-924.

88. Enzinger FM, Weiss SW. Soft tissue tumors. Mosby, St. Louis 1983; 78-83.

89. Rosenberg HS, Stenback WA, Spjut HJ. The fibromatoses of infancy and childhood. Perspect Pediatr Pathol 1978; 4: 269-348.

90. Wiswell TE, Sakas EL, Stephenson SR, et al. Infantile myofibromatosis. Pediatrics 1985; 76: 981-984.

91. Koujok K, Ruiz RE, Hernandez RJ. Myofibromatosis: imaging characteristics. Pediatr Radiol 2005; 35: 374-380.

92. Chung EB, Enzinger FM. Infantile myofibromatosis. Cancer 1981; 48: 1807-1818.

93. Baer JW, Radkowski MA. Congenital multiple fibromatosis. A case report with review of the world literature. Am J Roentgenol Radium Ther Nucl Med 1973; 118: 200-205.

94. Mizobuchi K, Yoshino T, Ikehara I, et al. Infantile myofibromatosis. Report of two cases. Acta Pathol Jpn 1986; 36: 1411-1418.

95. Okamoto K, Ito J, Takahashi H, et al. Solitary myofibromatosis of the skull. Eur Radiol 2000; 10: 170-174.

96. Queralt JA, Poirier VC. Solitary infantile myofibromatosis of the skull. AJNR Am J Neuroradiol 1995; 16: 476-478.

97. Hasegawa T, Hirose T, Seki K, et al. Solitary infantile myofibromatosis of bone. An immunohistochemical and ultrastructural study. Am J Surg Pathol 1993; 17: 308-313.

98. Inwards CY, Unni KK, Beabout JW, Shives TC. Solitary congenital fibromatosis (infantile myofibromatosis) of bone. Am J Surg Pathol 1991; 15: 935-941.

99. Agrawal V, Ludwig N, Agrawal A, Bulsara KR. Intraosseous intracranial meningioma. AJNR Am J Neuroradiol 2007; 28: 314315.

100. Tokgoz N, Oner YA, Kaymaz M, et al. Primary intraosseous meningioma: CT and MRI appearance. AJNR Am J Neuroradiol 2005; 26: 2053-2056. 
101. Gibson SE, Prayson RA. Primary skull lesions in the pediatric population: a 25-year experience. Arch Pathol Lab Med 2007; 131: 761-766.

102. Reigel D, Quigley M, Lin L. Pediatric skull tumors. In: McLaurin R, Schut L, Venes J (eds.). Pediatric Neurosurgery. Surgery of the Developing Nervous System. WB Saunders, Philadelphia 1989; 421.

103. Schneider RC, Gabrielsen TO, Hicks SP. Calvarial hemangioma. The value of selective external carotid angiography in surgical excision of the lesion. Neurology 1973; 23: 352-356.

104. Murphey MD, Fairbairn KJ, Parman LM, et al. Musculoskeletal angiomatous lesions: radiologic-pathologic correlation. Radiographics 1995; 15: 893-917.

105. Ortiz O, Schochet S, Bastug D. Imaging evaluation and clinicopathotolic correlation of mass lesions involving the calvaria. Part II: tumoral and inflammatory lesions. Int J Neuroradiol 1999; 5: 151-165.

106. Politi M, Romeike BFM, Papanagiotou P, et al. Intraosseous hemangioma of the skull with dural tail sign: radiologic features with pathologic correlation. Am J Neuroradiol 2005; 26: 2045-2052.

107. Koulouris G, Rao P. Multiple congenital cranial hemangiomas. Skeletal Radiol 2005; 34: 485-489.

108. Navarro OM, Laffan EE, Ngan BY. Pediatric soft-tissue tumors and pseudotumors: MR imaging features with pathologic correlation. I. Imaging approach, pseudotumors, vascular lesions, and adipocytic tumors. Radiographics 2009; 29: 887-906.

109. Ernemann U, Kramer U, Miller S, et al. Current concepts in the classification, diagnosis and treatment of vascular anomalies. Eur J Radiol 2010; 75: 2-11.

110. Moukaddam H, Pollak J, Haims AH. MRI characteristics and classification of peripheral vascular malformations and tumors. Skeletal Radiol 2009; 38: 535-547.

111. Berenguer B, Mulliken JB, Enjolras O, et al. Rapidly involuting congenital hemangioma: clinical and histopathologic features. Pediatr Dev Pathol 2003; 6: 495-510.

112. Dubois J, Garel L. Imaging and therapeutic approach of hemangiomas and vascular malformations in the pediatric age group. Pediatr Radiol 1999; 29: 879-893.

113. Dubois J, Alison M. Vascular anomalies: what a radiologist needs to know. Pediatr Radiol 2010; 40: 895-905.

114. Abernethy LJ. Classification and imaging of vascular malformations in children. Eur Radiol 2003; 13: 2483-2497.

115. Siegelman SS. Taking the X out of histiocytosis X. Radiology 1997; 204: 322-324.

116. Egeler RM, D’Angio GJ. Langerhans cell histiocytosis. J Pediatr 1995; 127: 1-11.

117. DiNardo LJ, Wetmore RF. Head and neck manifestations of histiocytosis-X in children. Laryngoscope 1989; 99: 721-724.

118. Ghanem I, Tolo VT, D’Ambra P, Malogalowkin MH. Langerhans cell histiocytosis of bone in children and adolescents. J Pediatr Orthop 2003; 23: 124-130.

119. Irving RM, Broadbent V, Jones NS. Langerhans'cell histiocytosis in childhood: management of head and neck manifestations. Laryngoscope 1994; 104: 64-70.

120. Meyer JS, Harty MP, Mahboubi S, et al. Langerhans cell histiocytosis: presentation and evolution of radiologic findings with clinical correlation. RadioGraphics 1995; 15: 1135-1146.
121. Howarth DM, Gilchrist GS, Mullan BP, et al. Langerhans cell histiocytosis: diagnosis, natural history, management, and outcomes. Cancer 1999; 85: 2278-2290.

122. Koch BL. Langerhans histiocytosis of temporal bone: role of magnetic resonance imaging. Top Magn Reson Imaging 2000; 11: 66-74.

123. Ochsner SF. Eosinophilic granuloma of the bone: experience with 20 cases. Am J Roentgenol Radium Ther Nucl Med 1966; 97: 719-726.

124. Huvos AG. Clinicopathologic spectrum of osteogenic sarcoma. Recent observations. Pathol Annu 1979; 14 Pt 1: 123-144.

125. Deutsch M. Radiation therapy in the treatment of tumors of the cranial base. In: Sekhar LN, Schramm VL (eds.). Tumors of the Cranial Base. Futura, New York 1987; 163.

126. Chirathivat S, Post MJ. CT demonstration of dural metastases in neuroblastoma. J Comput Assist Tomogr 1980; 4: 316-319.

127. Zimmerman RA, Bilaniuk L. CT of primary and secondary craniocerebral neuroblastoma. AJR Am J Roentgenol 1980; 135: 1239-1242.

128. Healy JF, Bishop J, Rosenkrantz H. Cranial computed tomography in the detection of dural, orbital, and skull involvement in metastatic neuroblastoma. J Comput Tomogr 1981; 5: 319-323.

129. Latchaw RE, L'Heureux PR, Young G, Priest JR. Neuroblastoma presenting as central nervous system disease. AJNR Am J Neuroradiol 1982; 3: 623-630.

130. D’Ambrosio N, Soohoo S, Warshall C, et al. Craniofacial and intracranial manifestations of Langerhans cell histiocytosis: report of findings in 100 patients. AJR Am J Roentgenol 2008; 191: 589-597.

131. Stiller CA, Bielack SS, Jundt G, Steliarova-Foucher E. Bone tumours in European children and adolescents, 1978-1997. Report from the Automated Childhood Cancer Information System project. Eur J Cancer 2006; 42: 2124-2135.

132. Hadfield MG, Luo VY, Williams RL, et al. Ewing's sarcoma of the skull in an infant. A case report and review. Pediatr Neurosurg 1996; 25: 100-104.

133. Kiritsi O, Noussios G, Tsitas K, et al. Anatomical variants of the emissary veins: unilateral aplasia of both, the sigmoid sinus and the internal jugular vein and development of the petrosquamosal sinus. A rare case report. Folia Morfol 2011; 70: 305-308.

134. Hershkovitz I, Greenwald C, Rothschild BM, et al. The elusive diploic veins: anthropological and anatomical perspective. Am J Phys Anthropol 1999; 108: 345-358.

135. Dubois J, Garel L. Imaging and therapeutic approach of hemangiomas and vascular malformations in the pediatric age group. Pediatr Radiol 1999; 29: 879-893.

136. Fordham LA, Chung CJ, Donnelly LF. Imaging of congenital vascular and lymphatic anomalies of the head and neck. Neuroimaging Clin N Am 2000; 10: 117-136.

137. Peyser E, Weissberg D. Post-traumatic arachnoidal cyst. Report of an unusual case. J Neurosurg 1961; 18: 551-553.

138. Sartawi M, Schwartz FT, Fox JL. An unusual osteolytic lesion of the skull due to a traumatic arachnoid cyst. Neuroradiology 1973; 6: $180-181$

139. Scarfò GB, Mariottini A, Tomaccini D, Palma L. Growing skull fractures: progressive evolution of brain damage and effectiveness of surgical treatment. Childs Nerv Syst 1989; 5: 163-167.

140. Mahapatra AK, Tandon PN. Post-traumatic intradiploic pseudomeningocele in children. Acta Neurochirurgica 1989; 100: 120-126. 
141. Agrawal D, Mishra S. Post-traumatic intradiploic pseudomeningocele. Indian Pediatrics 2010; 47: 271-273.

142. Sato TS, Moritani T, Hitchon P. Occipital intradiploic CSF pseudocyst: an unusual complication of a ventriculoperitoneal shunt malfunction. AJNR Am J Neuroradiol 2009; 30: 635-636.

143. Martínez-Lage JF, Martínez Pérez M, Domingo R, Poza M. Posttraumatic intradiploic arachnoid cyst of the posterior fossa. Childs Nerv Syst 1997; 13: 293-296.
144. Goldstein FP, Rosenthal SA, Garancis JC, et al. Varieties of growing skull fractures in childhood. J Neurosurg 1970; 33: 25-28.

145. Goldstein F, Sakoda T, Kepes JJ, et al. Enlarging skull fractures: an experimental study. J Neurosurg 1967; 27: 541-550. 